\title{
RÉGIMEN JURÍDICO DE LOS REQUERIMIENTOS DE INFORMACIÓN EFECTUADOS POR LAS AUTORIDADES DE COMPETENCIA*
}

\author{
JAVIER GUILlÉN CARAMÉS \\ Profesor Titular de Derecho Administrativo \\ Acreditado a Catedrático \\ Universidad Rey Juan Carlos
}

\begin{abstract}
RESUMEN
El Derecho de la Competencia configura las potestades de investigación de forma muy amplia y extensa, lo que en ocasiones puede entrar en conflicto o en colisión con diversos derechos fundamentales de los sujetos afectados por las actuaciones de investigación desarrolladas por las autoridades de competencia. Cómo se deben desarrollar las actuaciones inspectoras y qué derechos de las empresas pueden verse afectados por la actuación de las autoridades de competencia, en lo referente a los requerimientos de información que pueden solicitar las autoridades de competencia, así como qué garantías y límites tienen que observarse por las mismas en el curso de sus acciones, constituye el objeto de este trabajo.
\end{abstract}

Palabras clave: potestades de investigación; autoridades de competencia; requerimientos de información; protección de derechos fundamentales; discrecionalidad administrativa; principio de proporcionalidad; motivación; confidencialidad.

\begin{abstract}
The powers of enforcing investigative measures by the competition authorities have been established widely in Competition Law. These wide powers given to the competition administrative authorities can enter in conflict with different fundamental rights of undertakings when the investigations take place. The critical analysis of how this type of investigations should be carry on and which fundamental rights of undertakings could be affected, regarded with the formal requests for information that undertakings should provide to the competition authorities; and what is the scope and limits of the powers of investigation of the competition authorities, are the main purpose of this article.
\end{abstract}

Key words: powers of investigation; competition authorities; requests of information; protection of human rights; discretionary powers; principle of proportionality; reasoning; confidentiality.

* Este trabajo se ha realizado en el marco del Proyecto de Investigación «La potestad sancionadora de los organismos reguladores», otorgado por el Ministerio de Economía y Competitividad (DER2011-22549) y que se desarrolla en la URJC. 


\section{SUMARIO}

I. INTRODUCCIÓN.-II. LAS POTESTADES ADMINISTRATIVAS DE INVESTIGACIÓN DE LAS AUTORIDADES DE COMPETENCIA: 1. Reserva de Ley y base jurídica. 2. Finalidad y naturaleza de las investigaciones en el Derecho de la Competencia.-III. LAS ACTUACIONES DE INVESTIGACIÓN DE LA CNMC: EN ESPECIAL, LOS REQUERIMIENTOS DE INFORMACIÓN: 1. Ámbito subjetivo: el deber de colaboración de los sujetos investigados. 2. Ámbito objetivo. 3. Ámbito temporal.-IV. GARANTÍAS DE LOS SUJETOS OBJETO DE LOS REQUERIMIENTOS DE INFORMACIÓN: 1. El deber de motivación. 2. El principio de proporcionalidad. 3. El deber de sigilo. 4. El derecho de defensa como límite al deber de colaboración.-V. LÍMITES AL USO Y CESIÓN DE LA INFORMACIÓN OBTENIDA MEDIANTE LOS REQUERIMIENTOS DE INFORMACIÓN: EN ESPECIAL, LA CONFIDENCIALIDAD DE DETERMINADA INFORMACIÓN: 1 . Derecho a la confidencialidad en relación con los documentos objeto de los requerimientos de información: A) La delimitación del objeto de la confidencialidad. B) El tratamiento de la información confidencial. C) La prohibición de la utilización de la información para fines distintos a los establecidos en la legislación de competencia. 2. En especial, la confidencialidad en los documentos afectados por el derecho de defensa: A) Tipo de comunicaciones que se encuentran comprendidas bajo la confidencialidad. B) La inexistencia de un vínculo salarial entre empresa y abogado.-VI. BIBLIOGRAFÍA.

\section{INTRODUCCIÓN}

Uno de los ámbitos donde se prevé una intensa intervención de las Administraciones públicas tendentes a garantizar el orden económico es el Derecho de la Competencia. En este contexto existe un acuerdo generalizado respecto a la creciente importancia de la defensa de la competencia, que se ha ido configurando como uno de los elementos principales de la política económica de la actualidad. De este modo, debe señalarse que la defensa de la libre concurrencia complementa a otras actuaciones de regulación de la actividad económica y es un importante instrumento para promover la productividad de los factores y la competitividad general de la economía. Por estos motivos resulta necesario disponer de un sistema que permita contar con los instrumentos necesarios y adecuados para garantizar el buen funcionamiento del mercado en todo el ámbito de la Unión Europea.

Con esta finalidad se diseña un marco jurídico complejo de cara a la consecución de los objetivos que persigue el mantenimiento de una libre concurrencia empresarial de la que se puedan beneficiar los consumidores. De este modo, se aprobó en el ámbito comunitario el Reglamento (CE) 1/2003, de 16 de diciembre de 2002, del Consejo, de aplicación de las normas sobre competencia previstas en los artículos 101 y 102 del Tratado de Funcionamiento de la Unión Europea (TFUE), en 
el que se dota a la Comisión de importantes potestades de intervención sobre las empresas que actúen en el mercado europeo, especialmente desde la posibilidad de desarrollar actuaciones inspectoras con el objeto de poder detectar los acuerdos, decisiones y prácticas concertadas prohibidos por el artículo 101 TFUE, así como la explotación abusiva de una posición dominante prohibida por el artículo 102 TFUE.

A su vez, en España se aprobó la Ley 15/2007, de 3 de julio, de Defensa de la Competencia (LDC), desarrollada por el Reglamento 261/2008, de 22 de febrero (RDC), en el que se atribuyen importantes facultades a la nueva Comisión Nacional de los Mercados y de la Competencia (CNMC), creada mediante la Ley $3 / 2013$, de 4 de junio (LCNMC), así como a las autoridades de competencia autonómicas, de cara al desarrollo de actuaciones inspectoras sobre las empresas y asociaciones de empresas con la finalidad de vigilar la adecuación de sus conductas empresariales al marco de estas normas.

De este modo, la legislación de competencia configura las potestades de investigación de forma muy amplia y extensa, lo que en ocasiones puede entrar en conflicto o en colisión con diversos derechos fundamentales de los sujetos afectados por las actuaciones de investigación ${ }^{1}$. Cómo se deben desarrollar las actuaciones inspectoras y qué derechos de las empresas pueden verse afectados por la actuación de las autoridades de competencia, en lo referente a los requerimientos de información que pueden solicitar las autoridades de competencia, así como qué garantías y límites tienen que observarse por las mismas en el curso de sus acciones, constituye el objeto de este trabajo.

La problemática a la hora de afrontar este estudio es variada, fundamentalmente porque en ocasiones van a concurrir tres ordenamientos en la configuración del contenido de los derechos fundamentales de las empresas que se pueden ver afectados por las investigaciones que desarrolle la CNCM. Así, por un lado, en ocasiones van a ser los agentes de la Comisión los encargados de practicar las distintas actuaciones inspectoras recogidas en el Reglamento 1/2003, en numerosas ocasiones con el auxilio de las autoridades nacionales. De otro, las autoridades nacionales de competencia en el desarrollo de las actuaciones de investigación

\footnotetext{
1 Como señala M. Rebollo Puig, la LCNMC estructura su regulación de la inspección de forma amplia, distinguiendo dos grandes grupos de potestades de inspección. Por un lado, el artículo 27 se ocupa de potestades que se ejercen en el desarrollo de las visitas de inspección. Por otro lado, el artículo 28 se refiere a las potestades que se canalizan a través de requerimientos de escritos de información; vid. "Potestades inspectoras y sancionadoras», en La Comisión Nacional de los Mercados y de la Competencia (dir. M. CARLón RuIz), CivitasThomson Reuters, 2014, págs. 705 y ss. Igualmente, sobre la inspección en Derecho de la Competencia, vid. J. Guillén Caramés, Régimen jurídico de la inspección en Derecho de la Competencia, Aranzadi-Thomson Reuters, 2010, págs. 57 y ss.
} 
van a aplicar la LDC, si bien también podrán aplicar los artícuos 101 y 102 TFUE, lo que hará que entren en juego diversos ordenamientos jurídicos en la protección de los derechos de las empresas.

Además, a la hora de examinar qué derechos de las empresas se pueden ver afectados y qué límites y garantías deben guardarse por las autoridades de competencia en el curso de sus actuaciones conviene recordar la jurisprudencia de Estrasburgo, esto es, el Convenio Europeo de Derechos Humanos (CEDH), del que son parte todos los Estados miembros de la Unión Europea, la que ha ido definiendo los derechos de los sujetos pasivos de la inspección. A su vez y debido a que en numerosas ocasiones los agentes de la Comisión van a tener que solicitar el auxilio de las autoridades nacionales para proceder a una investigación en un Estado miembro, como he señalado anteriormente, ello va a dar entrada al ordenamiento jurídico nacional, especialmente en lo referido a la protección de los derechos fundamentales, por lo que habrá también que tener en cuenta la jurisprudencia constitucional para ver cómo configura y qué alcance da a dicho derecho.

\section{LAS POTESTADES ADMINISTRATIVAS DE INVESTIGACIÓN DE LAS AUTORIDA- DES DE COMPETENCIA}

\section{Reserva de ley y base jurídica}

Resulta evidente que las potestades administrativas de las que disponen las autoridades de competencia para desarrollar sus actuaciones inspectoras, entre las que se encuentran los requerimientos de información, inciden de manera directa en los derechos de los ciudadanos. Ello implica que dicha limitación de la libertad de los ciudadanos debe encontrarse amparada en normas con rango de ley que van a ser la base jurídica fundamental que permita amparar las inspecciones que puedan realizar las autoridades de competencia.

En el ordenamiento jurídico comunitario la reserva de ley se encuentra satisfecha por el Reglamento 1/2003, que delimita las potestades de la Comisión en el Derecho de la Competencia. Las inspecciones desarrolladas por los agentes de la Comisión, por sí mismos o auxiliados por las autoridades nacionales, no sólo deben respetar la normativa comunitaria, sino también el Derecho nacional del Estado en el que se practiquen. Así, por ejemplo, el juez nacional es el competente para autorizar la entrada en el domicilio de las empresas sujetas a la inspección, que, a su vez, será solicitada por las autoridades nacionales de competencia. 
Por su parte, en el ordenamiento español las actuaciones inspectoras están previstas en la LCNMC, concretamente en sus artículos 27 y 28 , en los que se atribuyen diversas potestades de inspección. Por un lado, el artículo 27 se centra en las inspecciones domiciliarias que se desarrollen sobre las empresas y asociaciones de empresas, mientras que el artículo 28 establece como otra modalidad de las actuaciones inspectoras que puede realizar la CNMC los denominados requerimientos de información.

En definitiva, puede afirmarse que las potestades de investigación en el Derecho de la Competencia se adecuan a la reserva de ley, elemento característico de toda actividad administrativa limitadora de derechos. A ello conviene añadir que, en el inicio de cualquier inspección, la orden en que se recoja la orden de investigación por parte de la CNMC para llevarla a cabo deberá contener claramente la base jurídica que sirve de fundamento legal a dicha actuación, así como tener delimitado lo más concretamente posible el ámbito objetivo sobre el que va a desplegarse dicha actuación, tal y como recoge el artículo 28.1, párrafo segundo, LCNMC: «los requerimientos de información habrán de estar motivados y ser proporcionados al fin perseguido. En los requerimientos que dicte al efecto, se expondrá de forma detallada y concreta el contenido de la información que se vaya a solicitar, especificando de manera justificada la función para cuyo desarrollo es precisa tal información y el uso que pretende hacerse de la misma».

\section{Finalidad y naturaleza de las investigaciones en el Derecho de la Competencia}

La actual LCNMC refuerza y consolida los poderes de la CNMC en materia de inspección respecto a la legislación anterior: precinto de locales, inspecciones en el domicilio particular de los empresarios, etc. Este aumento de las facultades de inspección se encuadra dentro de dos de los principios fundamentales sobre los que se sustenta la nueva LCNMC: la necesidad de garantizar la seguridad jurídica a los operadores económicos y la eficacia en la lucha contra las conductas colusorias, especialmente los cárteles. De este modo, como señaló la extinta CNC en su resolución Stanpa, de 3 de octubre de 2008, «la eficacia en la lucha contra las conductas restrictivas de la competencia no puede menoscabar en forma alguna la seguridad jurídica de los operadores y las empresas afectadas, en especial en lo que concierne a los derechos fundamentales de las mismas y del personal a su servicio, pero 
tampoco la aplicación del principio de seguridad jurídica debe olvidar el propósito marcado por la Ley de una lucha eficaz contra las conductas restrictivas de la competencia» ${ }^{2}$.

Por tanto, las inspecciones previstas en la normativa de competencia se erigen en una herramienta de suma importancia para lograr esta finalidad de lucha contra las conductas colusorias, especialmente los cárteles, que constituyen la conducta más perjudicial para la competencia en el mercado. Ha sido unánimemente aceptado por la doctrina económica y jurídica, tanto a nivel internacional como nacional, que esta modalidad de conducta anticompetitiva debe ser objeto de una persecución constante y sin tregua, para lo que las actuaciones inspectoras son una herramienta de investigación de primer orden de la que se sirven las autoridades de competencia en su intento de erradicarlas.

De esta manera, resulta importante destacar algunos elementos esenciales sobre los que se va a cimentar la función de investigación en este ámbito. En primer lugar, ha de señalarse la importancia que tiene en las inspecciones de competencia el elemento de sorpresa en la actuación de los inspectores, así como la necesidad de que el desarrollo de la investigación comience con carácter inmediato una vez se haya procedido a la notificación de la orden de investigación al representante de la empresa. Como han señalado las autoridades de competencia en diversas resoluciones ${ }^{3}$, «la propia naturaleza de la documentación que se busca confirma la especial importancia del carácter sorpresivo de las inspecciones en materia de la competencia».

A ello hay que añadir otro elemento determinante de la trascendencia que reviste el carácter sorpresivo de las inspecciones en el Derecho de la Competencia, que radica en el hecho de que normalmente se llevan a cabo varias inspecciones de forma simultánea, de tal manera que la demora en el inicio de una de ellas y la posibilidad de que ésta sea informada por el resto de las empresas en las que ya ha comenzado la actuación inspectora sobre el objeto de la misma podrían producir un alto riesgo de que se pudiera producir una eliminación de la información buscada, poniendo, por tanto, en serio peligro la eficacia de la inspección y la finalidad de la misma.

Igualmente, debe destacarse la relevancia que tiene en la actualidad en las diferentes actuaciones de investigación el uso de las nuevas tecnologías por parte de las empresas, especialmente en lo que se refiere al almacenamiento de información y documentación en un soporte in-

\footnotetext{
2 Expte. R/0006/08.

3 Así, entre otras, vid. resolución CASER, de 24 de julio de 2008 (Expte. SNC/02/08), o la resolución L'Oreal, de 3 de octubre de 2008 (Expte. R/0005/08).
} 
formático. Ello hace que las inspecciones de competencia deban tener en cuenta dos elementos adicionales. Por un lado, conviene hacer hincapié en el volumen de información sobre la que recae la inspección. En la actualidad es más que evidente que el ordenador personal de un empleado de una empresa sometida a una inspección puede contener mayor volumen de documentación que una dependencia de la empresa llena de archivos y expedientes. Este hecho puede ser repetido en toda la empresa, dando lugar a un volumen muy elevado de información sobre la que los inspectores deben ejercer sus funciones, sin poder interferir en el normal funcionamiento de la empresa.

De otro lado, el desarrollo de las nuevas tecnologías permite que la información existente en los servidores de las empresas sea fácilmente alcanzable, así como rápidamente eliminada por terceros situados en otros lugares (incluso en el extranjero) si se dispone de las herramientas informáticas adecuadas. Ello hace que la inspección en este ámbito material tenga una especial naturaleza respecto a otras modalidades inspectoras que se desarrollan en otros sectores.

III. LAS ACTUACIONES DE INVESTIGACIÓN DE LA CNMC: EN ESPECIAL, LOS REQUERIMIENTOS DE INFORMACIÓN

\section{1. Ámbito subjetivo: el deber de colaboración de los sujetos investigados}

La legislación de defensa de la competencia atribuye a los inspectores amplias facultades de cara a obtener información sobre la actividad objeto de control, imponiendo a los sujetos pasivos el correlativo deber de facilitar dicha información, como prescribe el artículo 28.1 LCNMC.

De este modo, la CNMC puede realizar requerimientos de información a toda persona física o jurídica, así como a los órganos y organismos de cualquier Administración pública, los cuales quedan sujetos al deber de colaboración con la CNMC en el ejercicio de la protección de la libre competencia, tal y como advierte el artículo 28.1 LCNMC $^{4}$.

Puede señalarse respecto a las Administraciones públicas que el deber de colaboración enunciado no es sino la plasmación del artículo 4

4 Como señala M. ReBollo Puig, el artículo 28.1 LCNMC impone al administrado un deber de hacer, en concreto de suministrar información, que en el caso de incumplimiento permita, en ciertas condiciones y supuestos, pasar a la ejecución forzosa, siquiera sea mediante multas coercitivas, sin perjuicio de que además tengan el respaldo de verdaderas sanciones, como ocurre en el caso de la obstrucción a la inspección; vid. "Potestades inspectoras...", op. cit., pág. 708 . 
LPC, que regula con carácter general este deber, así como el de información recíproca que se establece entre todas las Administraciones públicas. El apartado primero de dicho precepto establece que las Administraciones públicas deben actuar y relacionarse de acuerdo con el principio de lealtad institucional, en cuya virtud deberán: respetar el ejercicio legítimo por las otras Administraciones de sus competencias; ponderar, en el ejercicio de las competencias propias, la totalidad de los intereses públicos implicados, y en particular aquellos cuya gestión esté encomendada a las otras Administraciones públicas; facilitar la información que precisen sobre la actividad que desarrollen en el ejercicio de sus propias competencias, puesto que las Administraciones podrán solicitar cuantos datos, documentos o medios probatorios se hallen a disposición del ente público al que se envíe la solicitud; y prestar en el ámbito propio la cooperación y la asistencia activa que el resto de Administraciones pudiera recabar para el eficaz ejercicio de sus competencias ${ }^{5}$.

Del ejercicio de esta potestad de investigación por parte de las autoridades de competencia surge el deber de colaboración de los entes sujetos a dichos requerimientos de información y están obligados a proporcionar a requerimiento de la CNMC toda clase de datos e informaciones de que dispongan y que puedan resultar necesarios para el desarrollo de las funciones de dicha Comisión. En este sentido, la LDC tipifica como infracción leve en su artículo 62.2.c) el no haber suministrado a la CNMC la información requerida o haberla suministrado de forma incompleta, incorrecta, engañosa o falsa ${ }^{6}$. De igual modo, el

5 Como señala J. E. SORIANO GARcía, el fundamento del deber de colaboración y de información de las Administraciones públicas «no son solamente razones derivadas del principio de eficacia, sino puramente de justicia, las que en este caso subyacen en la exigencia de colaboración por parte de las demás Administraciones Públicas. Razones que abundan además en la independencia del tribunal (en la actualidad CNMC), al que no se le pueden ocultar datos disponibles por otras Administraciones, ya que el resultado puede ser fatal para el justiciable administrativo. Si se oculta esa información, la actuación del tribunal puede acabar siendo dependiente del conocimiento que tengan otras Administraciones Públicas, entorpeciendo su labor que, a la postre, no es otra que dar una solución ajustada a Derecho a las conductas realizadas en el mercado por los operadores económicos»; vid. Derecho Público de la Competencia, IDELCO-Marcial Pons, 1998, págs. 321 y ss.

6 La CNMC, en el asunto Mediapro, de 31 de julio de 2012 (Expte. SNC/0026/12), impuso una sanción de 200.000 euros por suministrar información incompleta y engañosa. En este sentido señaló que «tal y como ha quedado acreditado en este expediente sancionador, MEDIAPRO no sólo no aportó información cuando debía (cuando le fue requerida por la Dirección de Investigación) sobre los cinco contratos y adendas contractuales citados, sino que en el caso del nuevo contrato de adquisición de derechos audiovisuales con el REAL MADRID (...) aportó a la CNC información engañosa en la que daba a entender que en esa fecha sólo había firmado un contrato (...) cuando realmente había firmado dos instrumentos contractuales (...) siendo el contrato omitido el que extendía la relación contractual entre MEDIAPRO y el REAL MADRID hasta la temporada 2014-2015». 
artículo 62.2.e) LDC considera infracción leve la obstrucción por cualquier medio de la labor de inspección de la CNMC, pudiendo constituir obstrucción a la labor de investigación, entre otras conductas, el no presentar, o hacerlo de forma incompleta, incorrecta o engañosa, los libros o documentos solicitados por la CNMC en el curso de la inspección, el no responder a las preguntas formuladas por la CNMC o hacerlo de forma incompleta, inexacta o engañosa, o el romper los precintos ${ }^{7}$.

A su vez, y en parecidos términos, el Reglamento 1/2003 recoge expresamente en su artículo 18.1 esta facultad, señalando que "para la realización de las tareas que le asigna el presente Reglamento, la Comisión, mediante una decisión o una simple solicitud, podrá solicitar a las empresas y asociaciones de empresas que le faciliten toda la información que estime necesaria».

Conviene diferenciar dos vertientes de las facultades informativas que tienen atribuidas las autoridades de competencia. De un lado, se encuentra la facultad de acceder a los documentos relativos a la actividad objeto de inspección y de obligatoria tenencia por parte de los sujetos pasivos. En este sentido, además de la documentación industrial, mercantil y contable que el ordenamiento jurídico obliga a tener cumplimentada con carácter general, la legislación administrativa de competencia impone a los operadores privados la llevanza y conservación de registros y documentos relacionados con su actividad ${ }^{8}$.

Pues bien, esta documentación que los sujetos pasivos deben poseer o conservar debe estar a disposición de la CNMC, con objeto de comprobar su existencia y puesta al día. Así, el artículo 28.1 LCNMC establece que, a requerimiento de la CNMC, los titulares de las personas jurídicas o Administraciones públicas sujetas a investigación se encuentran obligados a exhibir y facilitar toda clase de datos e informaciones de que dispongan y que puedan resultar necesarios para el desarrollo de las funciones de inspección de la CNMC.

7 La resolución de la CNMC Grafoplas del Noroeste, de 1 de marzo de 2011 (Expte. SNC/ 0010/11), consideró que «la desaparición de los documentos relacionados en el párrafo 36 del acta de inspección durante la inspección realizada en la empresa Grafoplas del Noroeste SA, así como la evidente falta de colaboración posterior con el fin de facilitar tales documentos al equipo de inspección, constituyen una obstrucción de la labor inspectora (...)». Sobre este punto, vid. J. MARTín PASTOR, "Artículo 39», en Comentario a la Ley de Defensa de la Competencia, Civitas-Thomson Reuters, 3. ${ }^{\mathrm{a}}$ ed., 2012, págs. 743 y ss.

8 En este sentido, vid. J. A. E. VERVAELE, «Regulación comunitaria y aplicación operacional de los poderes de investigación, obtención y utilización de pruebas en relación a la infracción de intereses financieros de la Comunidad Europea», RVAP, núm. 52, 1998, págs. 307 y ss.; igualmente, $c f r$. al respecto, C. PALAO TABOADA, «La potestad de obtención de información de la Administración tributaria y sus límites», en Estudios de Derecho y Hacienda. Homenaje a César Albiñana, vol. II, Ministerio de Economía y Hacienda, Madrid, 1987, págs. 890 y ss. 
Junto a esta facultad de acceso a la documentación, las normas ordenadoras de la inspección en el Derecho de la Competencia reconocen la facultad de requerir y el consiguiente deber de suministrar cualquier clase de información que se estime necesaria para cerciorarse del cumplimiento de la legislación de competencia y de interés al caso, pudiendo requerir la clarificación de cuestiones dudosas. Así se desprende igualmente del artículo 28.1 LCNMC $^{9}$.

De este modo, mientras la primera de las vertientes de esta facultad consiste en un acceso a la fuente de información misma, gracias a su plasmación en un documento concreto, y, en consecuencia, únicamente requiere del sujeto pasivo una actuación de puesta a disposición del personal inspector de tales fuentes, en la segunda manifestación nos encontramos, en cambio, ante deberes legales que imponen al sujeto una obligación de prestar información, y que por ello resulta más difícil de fiscalizar.

Por otro lado, una de las consecuencias favorables a las empresas derivadas del cumplimiento del deber de colaboración con la CNMC puede ser la reducción del importe de la sanción, al poder ser tenida en cuenta como circunstancia atenuante, tal y como prevé el artículo 64.3.d) $\mathrm{LDC}^{10}$.

\section{2. Ámbito objetivo}

El artículo 28.1 establece un ámbito objetivo muy amplio sobre el que pueden versar los requerimientos de información. En este sentido dispone que los mismos pueden recaer sobre «toda clase de datos e informaciones de que dispongan y que puedan resultar necesarias para el desarrollo de las funciones de dicha Comisión».

De este modo queda configurado un ámbito material indeterminado que precisa de una cierta concreción por parte de las autoridades de competencia al ejercer sus potestades de investigación. Puede afirmarse que aquéllas gozan de un amplio margen de discrecionalidad para concretar cuáles son los documentos e informaciones que pueden ser necesarios para el desarrollo de sus funciones, esto es, el garantizar que la libre competencia no sea obstaculizada por los diversos operadores que desarrollan sus actuaciones en el mercado. La jurisprudencia ha sido bastante permisiva con las autoridades de competencia a la

9 Sobre este punto, vid. J. M. JoshuA, «Requests for information in EEC factfinding procedures», ECLR, vol. 3, núm. 2, 1982, págs. 173 y ss.

10 Así lo ha señalado la SAN de 30 de junio de 2011, recurso 510/2009. 
hora de delimitar el alcance del término «informaciones» y éste ha sido objeto de una interpretación amplia del modo que puede entenderse comprendido bajo el mismo cualquier documento en poder de las empresas, normalmente de naturaleza económica y que tenga relevancia para el objeto de las investigaciones que estén desarrollando la Comisión y la CNMC ${ }^{11}$.

Como acabo de señalar, las autoridades de competencia gozan de una considerable discrecionalidad a la hora de fijar qué información puede resultar necesaria para el eficaz desarrollo de sus funciones. En este sentido, la jurisprudencia en su función revisora del alcance de los requerimientos de información se ha limitado a comprobar el elemento de la «necesidad de la información», es decir, el tipo de información que debe ser considerada necesaria para ser objeto de un requerimiento de información debe ser interpretada en función de las finalidades para las que se otorgaron a las autoridades de competencia las facultades de investigación de que se trata. En este sentido, se puede entender que se satisface la exigencia de correlación entre el requerimiento de información y la presunta conducta infractora desde el momento en que puede considerarse legítimamente que dicho requerimiento guarda relación con la presunta infracción, en el sentido de que las autoridades de competencia pueden suponer razonablemente que la información o documento requerido les ayudará a determinar si tuvo lugar la supuesta infracción ${ }^{12}$.

A ello se debe añadir que las autoridades de competencia sólo pueden requerir que se les facilite información que pueda permitir verificar las presunciones de infracción que justifican la investigación y que

11 Vid. STJUE Solvay c. Comisión, 27/88; STG Thyseen Stahl c. Comisión, T-141/94; STG HFB and others c. Comisión, T-9/99; STG Corus UK c. Comisión, T-48/00.

12 En este sentido se ha expresado la jurisprudencia de Luxemburgo. La sentencia del TPI de 12 de diciembre de 1991, SEP c. Comisión, T-39/90, señala que «el concepto de informaciones necesarias (...) debe interpretarse en función de las finalidades para las que se otorgaron a la Comisión las facultades de investigación de que se trata». Del mismo modo, la sentencia del TG de 22 de marzo de 2012, Slovak Telekom c. Comisión, T-458/09 y T-171/10, ha establecido que «habida cuenta del tenor del artículo 18, apartado 1, del Reglamento 1/2003 y de su finalidad, y conforme a la jurisprudencia (...) procede considerar que las facultades de investigación previstas por dicho precepto sólo están supeditadas al requisito de que la información solicitada sea necesaria, según apreciación de la Comisión, para verificar las presunciones de infracción que justifican la investigación (...). Por consiguiente, toda interpretación del artículo 18, apartado 1 , del reglamento $1 / 2003$ que implique prohibir, por principio, que la Comisión solicite a una empresa información relativa a u periodo durante el cual no le resultaba aplicable la normativa de la Unión en materia de competencia, pese a que dicha información sea necesaria para detectar una eventual infracción de esa normativa a partir del momento en que ésta le fue aplicable, supondría privar a dicho precepto de efecto útil y sería contraria a la obligación de la Comisión de examinar minuciosa e imparcialmente todos los elementos pertinentes del asunto de que se trata». Sobre este punto, vid. L. ORTIZ BLANco, EU Competition Procedure, Oxford University Press, 2013, págs. 290 y ss. 
deben ser precisadas de forma concreta en la propia solicitud $\mathrm{u}$ orden de información.

De otro lado, debido a las amplias potestades de investigación y verificación que la legislación de competencia otorga a las autoridades administrativas encargadas de su aplicación, corresponde a éstas evaluar la necesidad de la información que se solicita a las empresas objeto de los requerimientos.

\section{3. Ámbito temporal}

Los requerimientos de información pueden ser solicitados en cualquier momento por parte de las autoridades de competencia. En este sentido, es claro el artículo 28.1 LCNMC cuando establece la obligación de toda persona física o jurídica de proporcionar toda clase de datos e informaciones de que disponga y que resulten necesarios para el ejercicio de las funciones de la CNMC.

No se precisa ni en la LCNMC ni en la legislación de competencia el momento en que pueden desarrollar este tipo de actuaciones las autoridades de competencia, ni tampoco el plazo en el que los sujetos obligados a aportar la información deben cumplir con dicho deber, por lo que será, con carácter general, en el momento en que las autoridades de competencia estimen necesario el ejercicio de este tipo de potestades de investigación, así como deberán determinar de forma concreta qué plazo conceden a las empresas para cumplir con el deber de colaboración y aportar la información requerida.

No obstante, de la praxis de las autoridades de competencia sí que pueden destacarse dos momentos concretos en los que suelen ser comunes los requerimientos de información: uno es el relativo a la apertura por parte de las autoridades de competencia de una información reservada, y otro es en el marco de vigilancia de las resoluciones sancionadoras de las autoridades de competencia.

Por lo que respecta a la información reservada, el artículo 49.2 LDC permite a la Dirección de Competencia realizar la misma con la finalidad de determinar con carácter preliminar si concurren las circunstancias que justifiquen la incoación de un expediente sancionador por vulneración de los artículos 101 y 102 TFUE y 1 y 2 LDC. Por lo tanto, es precisamente en estas diligencias preliminares cuando resulta necesario requerir a las empresas determinado tipo de información y de documentos con la finalidad de poder ver si determinadas conductas o actuaciones de las empresas pueden ser presuntas infracciones de la 
LDC. Debe señalarse que la información reservada no forma parte del procedimiento sancionador, puesto que se trata de indagaciones previas que tienen como principal objeto evitar que se incoen expedientes sancionadores sin un mínimo respaldo probatorio, aunque sea de naturaleza indiciaria ${ }^{13}$. Sin embargo, sí que deben incorporarse al expediente sancionador todos los documentos e informaciones obtenidos como consecuencia de los requerimientos de información efectuados durante la información reservada ${ }^{14}$.

Otro espacio temporal en el que se suelen desarrollar los requerimientos de información es en el marco de los expedientes de vigilancia de las resoluciones de la CNCM. La LDC prevé en su artículo 41 la potestad de vigilancia que ostenta la CNMC para garantizar el cumplimiento de las obligaciones, de las resoluciones y acuerdos que se adopten en aplicación de la misma, tanto en materia de conductas restrictivas como de medidas cautelares y de control de concentraciones. Esta potestad de vigilancia es de una gran relevancia en el ámbito del Derecho de la Competencia, especialmente en la persecución de las prácticas restrictivas, puesto que no sólo resulta relevante para el buen funcionamiento del mercado que se sancionen dichas prácticas, sino que además se garantice que las obligaciones que se han impuesto por las autoridades de competencia a las empresas sancionadas sean realmente puestas en ejecución.

Asimismo, como señala la sentencia del TS de 3 de marzo de 2009, la función de la «DICNC de vigilar la ejecución y el cumplimiento de las

13 Vid. J. M. a BAÑo LEON, «Artículo 49 LDC», en Comentario a la LDC, Thomson ReutersCivitas, 2012, pág. 882.

${ }_{14}$ Como señala M. López BeníteZ, «la finalidad de la información reservada no es tanto juzgar sobre la inconveniencia o inconveniencia de incoar un procedimiento, como pareciera deducirse de una interpretación literal del artículo 69.2 LRJ-PAC, cuanto indagar acerca de si existen elementos suficientes que justifiquen la apertura de un procedimiento administrativo. (...) los dos objetivos o finalidades que alientan la existencia de la información reservada: por un lado, constatar la presencia de circunstancias que justifiquen la incoación de un procedimiento administrativo, sancionador en este caso, ya que con frecuencia pueden presentarse denuncias, cuyo relato no resulte suficientemente esclarecedor ni para determinar sin más trámite el archivo de la denuncia y la no iniciación, en consecuencia, de procedimientos alguno al respecto, ni para proceder tampoco aligeradamente a acordar tal apertura, extremo éste sobre el que la Administración debe ser cautelosa, particularmente en lo que concierne a los procedimientos sancionadores, por las gravosas e ignominiosas consecuencias que aquella determinación lleva en numerosos casos aparejada. Por otro lado, la información reservada incorpora un componente de preparación o facilitación del futuro procedimiento, ya que su objeto consiste (...) en determinar con la mayor precisión posible los hechos susceptibles de motivar la incoación del procedimiento, la identificación de la persona o personas que pudieran resultar responsables y las circunstancias relevantes que concurran en unos y otros (...)»; vid. "Algunas consideraciones en torno a la práctica de una información reservada en los procedimientos sancionadores en materia de defensa de la competencia», en Cuestiones actuales del procedimiento sancionador en Derecho de la Competencia (dir. J. Guillén Caramés), Civitas-Thomson Reuters, 2013, págs. 78 y ss. 
resoluciones que se adopten incluye la función de apreciar el cambio de circunstancias y proponer al CCNC las modificaciones procedentes».

De este modo, puede resultar necesario con el fin de verificar que una determinada empresa está cumpliendo con la resolución sancionadora el efectuar determinados requerimientos de información a la misma. Así ha ocurrido en el asunto Mediapro ${ }^{15}$, en el que la Dirección de Investigación de la $\mathrm{CNC}$ requirió en varias ocasiones a dicha empresa la aportación de determinada información concerniente a los contratos de adquisición de derechos audiovisuales de los clubes de fútbol, a fin de poder comprobar el cumplimiento de la resolución sancionadora de la CNMC de 14 de abril de $2010^{16}$. En concreto, el Consejo de la CNMC consideró «que toda la información requerida está directamente relacionada con la necesidad de dar cumplimiento a la obligación de vigilancia (...) que pesa sobre la Dirección de Investigación, sin que los requerimientos de información realizados se puedan considerar desproporcionados a ese fin. En este sentido, la Dirección de Investigación con carácter general ha concedido los aplazamientos solicitados por MEDIAPRO para contestar a los requerimientos de información y nunca le ha solicitado contratos que fueran previamente aportados en el marco del sancionador...».

\section{Garantías de los sujetos objeto de los ReQuerimientos DE INFORMACIÓN}

La legislación de competencia al atribuir las potestades de investigación se ve obligada a atribuir a las autoridades de competencia con cierta amplitud este tipo de potestades, ya que no puede preverse ni tomar en consideración la gran variedad de supuestos, su mayor o menor incidencia en los intereses generales, la necesidad de los datos que se tengan que recabar para el eficaz desarrollo de las funciones de la CNMC. De este modo, resulta necesario que en el transcurso de sus investigaciones la CNMC tenga que observar una serie de principios o de límites generales al ejercicio de sus potestades de cara a salvaguardar

15 Resolución CNC de 31 de julio de 2012 (Expte. SNC/0026/12).

16 En esta resolución de 14 de abril de 2010 se declaró que los contratos de adquisición de derechos audiovisuales de Liga y Copa de S. M. el Rey (excepto la final) de clubes de fútbol analizados en el expediente de referencia con una duración superior a tres temporadas son acuerdos entre empresas que, por sus efectos, caen bajo la prohibición de los artículos 1 de la LDC y 101 del TFUE. Por lo tanto, se intimó a las empresas que eran parte de esos acuerdos a que cesen en las conductas prohibidas y a que se abstengan de realizarlas en el futuro. 
determinados derechos de los entes objeto de investigación, especialmente los derivados de la protección de sus derechos fundamentales.

\section{El deber de motivación}

Las amplias facultades de investigación que la legislación de competencia atribuye a las autoridades de competencia deben encontrarse limitadas por determinadas garantías, dirigidas fundamentalmente a evitar las actuaciones arbitrarias y desproporcionadas, así como la realización de requerimientos de información, sin que dichas autoridades dispongan de ningún tipo de indicio sobre una presunta infracción por parte de las empresas objeto de investigación.

Por lo tanto, la motivación de los requerimientos de información constituye un elemento fundamental de la legalidad de las actuaciones de investigación realizadas por las autoridades de competencia. Así lo ha recogido la jurisprudencia del TJUE en el asunto E.On Energie c. Comisión, al establecer que

«la motivación exigida (...) debe adaptarse a la naturaleza del acto de que se trate y debe mostrar de manera clara e in-equívoca el razonamiento de la institución de la que emane el acto, de manera que los interesados puedan conocer las razones de la medida adoptada y el órgano jurisdiccional competente pueda ejercer su control. La exigencia de motivación debe apreciarse en función de las circunstancias de cada caso, en particular del contenido del acto, la naturaleza de los motivos invocados y el interés que los destinatarios u otras personas afectadas directa e individualmente por dicho acto puedan tener en recibir explicaciones. No se exige que la motivación especifique todos los elementos de hecho y de Derecho pertinentes, en la medida en que la cuestión de si la motivación de un acto cumple las exigencias del artículo 253 CE (en la actualidad 296 TFUE) debe apreciarse en relación no sólo con su tenor literal, sino también con su contexto, así como con el conjunto de normas jurídicas que regulan la materia de que se trate» ${ }^{17}$.

17 T-141/08, de 15 de diciembre de 2010. Esta sentencia fue objeto de recurso de casación ante el TJUE, que desestimó el mismo en su sentencia de 22 de noviembre de 2012 (C-89/11 P). 
Resulta claro que las empresas o Administraciones sujetas al deber de colaboración con la CNMC al ser requeridas por ésta para el suministro de determinada información, sólo van a poder cumplir fielmente con el mismo si comprenden de forma clara y precisa el alcance de dicho deber, así como poder preservar sus derechos de defensa. En este sentido se expresa la sentencia del TG de 26 de noviembre de 2014 en el asunto EP Investment c. Comisión, al señalar que

«las medidas de investigación adoptadas por la Comisión durante la fase de investigación preliminar, en especial las solicitudes de información (...) implican por su naturaleza la imputación de una infracción y pueden producir repercusiones importantes sobre la situación de las empresas sospechosas. En consecuencia, debe evitarse que el derecho de defensa pueda quedar irremediablemente comprometido durante esta fase del procedimiento administrativo ya que las medidas de investigación practicadas pueden tener un carácter determinante para la constitución de pruebas del carácter ilegal de las conductas de las empresas susceptibles de generar la responsabilidad de éstas. Por tanto, incumbe a la Comisión indicar, con tanta precisión como sea posible, lo que se busca y los elementos sobre los que debe versar la inspección».

Por tanto, el objeto del requerimiento de información debe estar debidamente motivado y deberá exponer de forma detallada y concreta el contenido de la información que se vaya a solicitar, especificando de manera justificada la función para cuyo desarrollo es precisa tal información y el uso que pretende hacerse de la misma, tal y como prevé el artículo 28.1 LCNMC ${ }^{18}$.

18 El TG de la UE, en sus sentencias de 14 de marzo de 2014, Cementos Portland Valderribas c. Comisión (T-296/11) y Schwenk Zement c. Comisión (T-306/11), ha recordado que las facultades de investigación no son ilimitadas y que deben desarrollarse con las necesarias garantías procesales que eviten situaciones desproporcionadas y permitan a las empresas investigas conocer con suficiente claridad el alcance de su deber de colaboración. Sobre este tema, vid. H. González DuRANTEZ, «Los límites a los requerimientos de información de la Comisión Europea», en Problemas prácticos y actualidad del Derecho de la Competencia (Anuario 2014), Thomson Reuters-Civitas, 2014, págs. 242 y ss. 


\section{El principio de proporcionalidad}

Los requerimientos de información deben ser proporcionados al fin perseguido, tal y como recoge el artículo 28.1.2. ${ }^{a}$ LCNMC. Esta previsión recogida en la LCNMC no es más que la plasmación del principio general de proporcionalidad que debe presidir el ejercicio de las potestades de inspección que desarrollen las autoridades de competencia. Así se recoge con carácter general en el artículo 39.bis.1 LPC, señalando a tal efecto que «las Administraciones Públicas que en el ejercicio de sus respectivas competencias establezcan medidas que limiten el ejercicio de derechos individuales o colectivos o exijan el cumplimiento de requisitos para el desarrollo de una actividad, deberán elegir la medida menos restrictiva, motivar su necesidad para la protección del interés público así como justificar su adecuación para lograr los fines que se persiguen, sin que en ningún caso se produzcan diferencias de trato discriminatorias».

De este modo, la potestad referida a la posibilidad que tiene la CNMC de realizar requerimientos de información sólo puede ejercerse cuando y en la medida en que sea proporcionada, sólo en tanto que sea imprescindible. Por lo tanto, no sólo debe la autoridad de competencia optar por la potestad menos restrictiva, sino también ejercerla de la forma menos gravosa para los sujetos investigados. En base a la aplicación de este principio de proporcionalidad, la CNMC deberá determinar el grado de intensidad de los requerimientos, si se pueden exigir más o menos documentos, si procede la retención de documentación o si, por ejemplo, resulta necesaria una inspección domiciliaria. Así lo ha recogido el TG en el asunto France Telecom, de 8 de marzo de 2007, al indicar que

«corresponde, en principio, a la Comisión determinar si una información es necesaria para poder descubrir una infracción de las normas sobre competencia y, aunque disponga ya de indicios o incluso de elementos probatorios sobre la existencia de una infracción, la Comisión puede legítimamente considerar necesario ordenar inspecciones adicionales que le permitan delimitar mejor la infracción o su duración (...)»; y añade posteriormente: "el hecho de que la Comisión dispusiera ya de determinados datos que indicaban que la demandante aplicaba tarifas contrarias al art. 82 TCE o que el Consejo [francés] de defensa de la competencia ya hubiera obtenido dichos datos y que, por tanto, pudiera transmitírselos a la Co- 
misión, no es suficiente para considerar desproporcionada la decisión impugnada ${ }^{19}$.

Igualmente, queda sujeta al control de proporcionalidad la elección del medio dirigido a las empresas objeto de la investigación para desarrollar el requerimiento de información. Así lo establece el TG en su sentencia de 14 de marzo de 2014, asunto Cemex c. Comisión ${ }^{20}$, en que ante el argumento sostenido por la Comisión de que, en virtud del artículo 18.1 del Reglamento 1/2003, podía optar discrecionalmente entre el envío de una decisión o una simple solicitud de información, el TG le recuerda que la opción que debe realizar entre uno u otro medio de requerimiento de información se encuentra sujeta al control de proporcionalidad, de tal modo que este control ha de realizarse en función de las necesidades de la investigación adecuada y teniendo en cuenta las particularidades del caso concreto. Si bien en el presente caso el TG termina señalando que las Decisiones recurridas se inscribían en el marco de una investigación sobre prácticas restrictivas de la competencia que precisaba de la presentación de información adicional o más precisa respecto de la ya aportada a la Comisión; y, además, debía tenerse en cuenta que esta investigación afectaba a ocho grupos de empresas en el sector del cemento. Por ello, el TG concluye que no parecía desproporcionado ni desmesurado que la Comisión hiciese uso de una Decisión, que es el instrumento jurídico que le aporta mayor garantía de obtener una respuesta completa y dentro del plazo fijado ${ }^{21}$.

Se aplica también el test de proporcionalidad al control del establecimiento del plazo concedido a los sujetos obligados a enviar la información requerida. En este sentido, el TG consideró insuficiente el plazo otorgado a una empresa tanto para recopilar la información como para garantizar el carácter completo, exacto y no engañoso de la información suministrada ${ }^{22}$.

\section{El deber de sigilo}

Durante el transcurso de las actuaciones inspectoras, y en particular en el caso de la visita y de los requerimientos o solicitudes de información, los inspectores pueden acceder a datos e informaciones

19 T-339/04. Del mismo modo, vid. J. C. LAGUnA DE PAZ, «Las potestades administrativas de investigación en materia de defensa de la competencia», $R D C y D$, núm. 5, 2009, pág. 39.

$20 \mathrm{~T}-292 / 11$

21 Vid. H. GonzÁlez Durantez, «Límites a los requerimientos...», op. cit., pág. 253.

22 Asunto Schwenk Zement c. Comisión (T-306/11), de 14 de marzo de 2014. 
susceptibles de afectar a la intimidad de los sujetos afectados por la inspección o a sus secretos comerciales. Debido a ello, uno de los deberes esenciales de los inspectores de competencia es el de no revelar los datos, informes o antecedentes de que puedan haber tenido conocimiento en el desempeño de sus funciones ${ }^{23}$. Y, en este sentido, el Reglamento 773/2004, de 7 de abril, relativo al desarrollo de los procedimientos de la Comisión con arreglo a los artículos 101 y 102 del TFUE, dispone en su artículo 16.1 lo siguiente: «La Comisión no comunicará ni dará acceso a la información, incluidos los documentos, si contiene secretos comerciales u otro tipo de información confidencial sobre cualquier persona» 24 .

De forma más explícita, el artículo 43.1 de la LDC regula este deber al señalar que «todos los que tomen parte en la tramitación de expedientes previstos en esta Ley o que conozcan tales expedientes por razón de profesión, cargo o intervención como parte, deberán guardar secreto sobre los hechos que hayan tenido conocimiento a través de ellos y de cuantas informaciones de naturaleza confidencial hayan tenido conocimiento en el ejercicio de sus cargos, incluso después de cesar en sus funciones».

Igualmente, el artículo 28.2 LCNMC prevé este deber de sigilo al disponer en su párrafo segundo que «quien tenga conocimiento de estos datos estará obligado a guardar sigilo respecto de los mismos».

No obstante, debe realizarse alguna precisión respecto este deber. La doctrina diferencia entre un deber genérico de discreción o sigilo y un deber específico de secreto. Mientras que el deber de sigilo puede configurarse como un deber personal de discreción, común a todos los funcionarios, el deber de secreto se refiere a determinados asuntos que se encuentran investidos de naturaleza secreta. Así, siguiendo criterios empleados por la doctrina italiana, puede señalarse que el deber de

23 Asimismo, este deber de sigilo puede extenderse al personal sin funciones inspectoras que presta sus servicios en el SDC. Sobre este punto, vid. L. MaRTín Rebollo, «Régimen de responsabilidades del inspector de consumo como funcionario en los ámbitos civil, penal y administrativo. Referencia al deber de sigilo», en La inspección..., cit., págs. 83 y ss.

24 El TPI, en su sentencia de 12 de diciembre de 1991, asunto T-39/90, SEP contra Comisión, puso de manifiesto que la protección de la confidencialidad de determinados datos obtenidos por la inspección se muestra de dos formas. Por un lado, «este artículo [20 del Reglamento 17/62] prohíbe, en su apartado 2, la divulgación de informaciones recogidas en aplicación del Reglamento núm. 17 y que, por su propia naturaleza, se hallan amparadas por el secreto profesional. Por otro lado, el artículo 20 prohíbe, en su apartado 1, la utilización de las informaciones recogidas en aplicación del Reglamento núm. 17, más que para el fin para el que hayan sido pedidas». Como declara el TPI en esta sentencia, «estas dos garantías, que presentan un carácter complementario, se refieren no sólo a la Administración comunitaria, sino también a las administraciones nacionales». En el mismo sentido se pronunció el TJCE en la sentencia de 16 de julio de 1992, asunto C-67/91, AEB contra Tribunal de Defensa de la Competencia. 
sigilo tiene carácter subjetivo o personal, pues es connatural a la cualidad del sujeto que detenta la información —al agente público—, con independencia del contenido de la información, puesto que este deber alcanza, en principio, a todas las informaciones que conozca en ejercicio de su función ${ }^{25}$. En cambio, el deber de secreto tiene un carácter objetivo o real, puesto que se encuentra conectado a la protección de intereses concretos, ya sean públicos o privados. Por tanto, el deber de los inspectores será el general de sigilo o el cualificado de secreto en función de la naturaleza de las informaciones de que se tenga conocimiento.

En todo caso, se tratará del deber cualificado de secreto en aquellas materias o sectores en los que la ley establezca el carácter reservado de los datos e informaciones obtenidos por la Administración. Así, por ejemplo, como puede observarse del precepto citado, los agentes de la Comisión deberán respetar, en todo caso, la confidencialidad de aquellos datos de carácter personal que puedan afectar a la intimidad de los sujetos inspeccionados, especialmente aquellos relativos a la confidencialidad de la documentación industrial, mercantil y contable de las empresas ${ }^{26}$.

Esta diferenciación explica que en el caso del deber de secreto éste permanece incluso después de haber cesado en el ejercicio de las funciones inspectoras, pues se trata de preservar la confidencialidad de la información aun cuando el inspector se encuentre desvinculado de la organización administrativa. Pero del mismo modo hay que tener presente que dado que con el deber de secreto se trata de proteger normalmente intereses privados, los titulares de los mismos pueden disponer de ellos.

Finalmente, con el propósito de garantizar la protección de la que pueda ser considerada información confidencial que, en diversas ocasiones, no será conocida por los inspectores de competencia, el Reglamento 773/2004 impone el deber sobre las empresas inspeccionadas de indicar qué documentos o partes de los mismos pueden contener, a su juicio, secretos comerciales u otro tipo de información confidencial, con

25 En este sentido, F. SAInz MoReno señala que el deber de sigilo no se refiere a temas, asuntos o documentos concretos, sino que cubre, en general, todo aquello que se conoce por razón del cargo, incluido el funcionamiento interno de la Administración; vid. "Secreto e información en Derecho Público», en Estudios sobre la Constitución española. Homenaje al Prof. Eduardo García de Enterría, vol. II, Civitas, 1991, pág. 2892. Igualmente, cfr. R. GARcía Macho, Secreto profesional y libertad de expresión del funcionario, Tirant lo Blanch, Valencia, 1994, págs. 31 y ss.; S. FERnÁndez Ramos, La actividad de inspección, Comares, Granada, 2002, págs. 248 y ss.

26 Vid. M. Pedraz Calvo, «La confidencialidad del expediente administrativo», en Anuario de la Competencia 1997, Marcial Pons-ICO, Madrid, 1998, págs. 174 y ss. 
el fin de que los agentes inspectores puedan cumplir correctamente con su deber de sigilo o secreto. De tal modo que cuando las empresas no cumplan con este deber la Comisión podrá presumir que los documentos o declaraciones afectados por la inspección no contienen información confidencial.

De todas formas, la LDC y la LCNMC prevén el incumplimiento por parte de las autoridades de competencia de este deber de sigilo en sus artículos 43.2 y 28.2.2. ${ }^{a}$ in fine, que «sin perjuicio de las responsabilidades penales y civiles que pudieran corresponder la violación del deber de secreto se considerará falta disciplinaria muy grave».

El TJUE extiende también a la debida diligencia en el tratamiento de las informaciones confidenciales que bajo esta condición llegan al conocimiento de los inspectores de competencia. Así puede destacarse el caso Adams, en el que el Tribunal condena por responsabilidad extracontractual a la Comisión por los perjuicios sufridos por el señor Adams $^{27}$. En concreto, los hechos de este asunto giraban en torno a este antiguo empleado de la empresa Hoffman-La Roche que sufrió condena en un procedimiento penal por infidelidad con su empresa. La deslealtad consistía en haber facilitado a la Comisión, a condición de que se mantuviera la reserva necesaria, información sobre el funcionamiento interno de la citada empresa. En la sentencia que condenó a Hoffmann-La Roche ${ }^{28}$ por abuso de posición dominante en un mercado tan delicado como el de las vitaminas coadyuvó decisivamente la información proporcionada por el señor Adams. En este sentido, el TJCE reprocha a la Comisión la falta de diligencia en proteger el anonimato del denunciante, negligencia que llevó al citado empleado a una condena penal en Suiza. Al respecto, el TJCE señaló:

«Por lo que hace a la existencia de una obligación de secreto, conviene notar que el artículo 214 del Tratado prevé una obligación, especialmente para los miembros y agentes de las instituciones de la Comunidad, de no divulgar informaciones que por su naturaleza misma están cubiertas por el secreto profesional, y esencialmente las notificaciones relativas a las empresas concernientes a sus relaciones comerciales o a los elementos de sus precios de venta. Si esta disposición atiende sobre todo a las calificaciones recibidas desde las empresas, la expresión especialmente muestra que se trata de un principio ge-

27 STJCE de 7 de noviembre de 1985, asunto 53/84.

28 STJCE de 13 de febrero de 1979 , asunto 85/76. 
neral que se aplica también a las informaciones suministradas por personas físicas si estas informaciones son por su naturaleza confidenciales. Tal es sobre todo el caso de informaciones suministradas a título puramente voluntario, pero sujeta a petición de confidencialidad para proteger el anonimato del informador: la institución que acepta recibir estas informaciones está obligada a respetar tales condiciones» ${ }^{29}$.

Esta jurisprudencia se vio respaldada por la sentencia del TG, de 1 de abril de 1993, BPB Industries y British Gypsum contra Comisión ${ }^{30}$, en la que el Tribunal confirmó la decisión de la Comisión de no comunicar determinados aspectos del expediente a la empresa afectada, en la medida en que ello suponía revelar el nombre de otras empresas que habían colaborado con la Comisión y que podían verse posteriormente afectadas $^{31}$.

\section{El derecho de defensa como límite al deber de colaboración}

En cierta conexión con el derecho a la confidencialidad de determinados documentos, como examinaremos más adelante, se encuentra el debate acerca del derecho a la no autoinculpación respecto a los requerimientos de información. La cuestión estriba en determinar si la empresa afectada puede ser obligada a responder a un requerimiento de entrega de información o a ofrecer determinadas explicaciones en el curso de una inspección que desarrollen las autoridades de competencia de las que se puede derivar o desprender su inculpación y, por tanto, puede ser contrario al artículo 24.2 de la CE, que establece el derecho a no declarar contra sí mismo.

El Tribunal Europeo de Derechos Humanos (TEDH) ha tenido ocasión de entrar en este debate a raíz de su sentencia, de 25 de febrero de

29 STJCE Adams.

30 Asunto T-65/89. Sobre esta problemática, vid. L. Ortiz Blanco, EC Competition Procedure, Oxford University Press, 2006, págs. 347 y ss.; J. Faull y A. NiKPaY, The EC Law of Competition, Oxford University Press, 2007, págs. 117 y ss.; L. RITTER y D. BRAUn, European Competition Law, Kluwer Law International, 2004, págs. 1040 y ss.

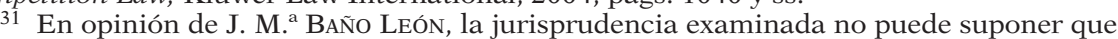
la Comisión pueda prevalerse de esta información sustraída al escrutinio del interesado y utilizarla como prueba. Cuestión distinta será que esa información sirva de forma indirecta para justificar nuevas indagaciones de la Comisión y para reforzar las líneas de investigación; vid. Potestades administrativas..., cit., págs. 206 y ss. Cfr., igualmente, T-353/94, Postbank contra Comisión. 
1993, Funke contra Francia. En este pronunciamiento jurisprudencial introduce un nuevo elemento de debate en la delimitación del contenido del derecho a no declarar contra sí mismo.

Por vez primera, el TEDH reconoce que dicho derecho forma parte del contenido del artículo 6.1 del CEDH y condena a Francia por haberlo vulnerado, al permitir su legislación que se procesara penalmente a un ciudadano alemán residente en Francia por no facilitar información sobre el movimiento de sus cuentas corrientes en Alemania.

La legislación de aduanas francesa permitía imponer, mediante el correspondiente proceso penal, penas privativas de libertad de diez días a un mes, y multas de 600 a 3.000 francos, a quien rehusara comunicar los documentos requeridos por las autoridades. Además, autorizaba la imposición de multas coercitivas por cada día de retraso en cumplir con su obligación. El señor Funke fue condenado a pagar una multa de 1.200 francos y a presentar los extractos bancarios, bajo pena de multa de 20 francos diarios por cada día de retraso.

El TEDH, con una débil argumentación, sostiene la siguiente postura:

«El tribunal constata que las aduanas provocaron la condena de M. Funke para obtener ciertas pruebas, cuya existencia presuponía sin tener certeza. Al margen de poder o querer procurárselas por otro medio, intentaron compeler al recurrente para que suministrara él mismo la prueba de las infracciones que había cometido. Las particularidades del derecho aduanero no pueden justificar una vulneración tal del derecho de todo "acusado", en el sentido autónomo que el artículo $6 .^{\circ}$ atribuye a este término, de guardar silencio y no contribuir a su propia incriminación».

La conclusión del TEDH es rotunda, como ha señalado J. M. ${ }^{a}$ BAÑo LEÓN, e interpretada literalmente podía dar lugar a pensar que el estándar de protección del artículo $6 .^{\circ}$ prohíbe cualquier medida aflictiva para exigir la entrega de documentos ${ }^{32}$. Esta interpretación podría suponer la condena de la legislación de todos los países europeos que obligan a las empresas por motivos fiscales, aduaneros o de seguridad (a los que se podrían añadir los de defensa de la competencia) a colaborar con la Administración, previendo multas coercitivas o presu-

\footnotetext{
32 Potestades administrativas..., cit., pág. 199.
} 
miendo la culpabilidad en caso de negativa de la empresa a suministrar la información.

Frente a esta posición puede discreparse en un doble sentido. Por un lado, no parece que ésa fuera la intención del TEDH; más bien parece que se ha querido llamar la atención sobre la existencia de ciertos límites. En el caso examinado, la legislación permitía inculpar penalmente a un ciudadano por no facilitar información, y esto es lo que precisamente puede haber parecido desproporcionado al TEDH y, por consiguiente, al artículo $6 .^{\circ}$ del Convenio ${ }^{33}$. Y, por otro lado, el presente asunto se refería a una persona física; si bien con la jurisprudencia más reciente del TEDH nada indica que las personas jurídicas queden excluidas de esta garantía ${ }^{34}$.

A su vez, en el ordenamiento jurídico comunitario no existía previsión expresa respecto al derecho de las empresas a no autoinculparse en la tramitación de expedientes por parte de la Comisión para la aplicación de derecho de la competencia. Incluso, como estudió Ll. CASES, los antecedentes del Reglamento 17 ponen de relieve que el Consejo al aprobarlo era consciente de la problemática que podía originar esa ausencia y que, pese a ello, decidió expresamente no incorporar ninguna previsión que reconociese ese derecho, al igual que ha ocurrido con el nuevo Reglamento 1/2003, que sustituye al anterior ${ }^{35}$.

33 De hecho, en la opinión concordante del juez MATSCHER, dice expresamente que «el hecho de que en las legislaciones fiscales quien no presenta los documentos requeridos sea sometido a multas previstas en la ley o acordadas por la Administración, o incluso se le considera obligado hacia el Fisco, no son en sí mismas contrarias ni a las exigencias del proceso equitativo ni a la presunción de inocencia. Pero en el asunto analizado, las autoridades francesas, al emplear procedimientos penales, habrían sobrepasado los límites del artículo 6. ${ }^{\circ}$.

34 Por lo que respecta a las condiciones de aplicación del artículo 6 CEDH, la referencia que hace a toda persona hay que entenderla hecha tanto a las personas físicas como a las jurídicas, tal y como ya señalara el Dictamen de la Comisión Europea de Derechos Humanos, anexo al TEDH, sentencia TEDH Stenuit, de 27 de febrero de 1992. Igualmente, $c f r$. STEDH de 17 de diciembre de 1996, Saunders contra Reino Unido.

De todas formas, es curioso cómo el Reglamento 1/2003 recoge esta jurisprudencia en el artículo 12, dedicado a regular el intercambio de información entre las autoridades de competencia, estableciendo en su apartado 3 lo siguiente: «La información intercambiada (...) únicamente podrá utilizarse como medio de prueba para imponer sanciones a las personas físicas (...) cuando la información se haya obtenido respetando el mismo nivel de protección de los derechos de defensa de las personas físicas que el que establecen las normas nacionales de la autoridad receptora. Sin embargo, en este caso, la información intercambiada no podrá ser utilizada para imponer penas privativas de la libertad».

35 Vid. Derecho administrativo..., cit., pág. 155. Por ello, J. M. Joshua consideró que «el privilegio contra la autoinculpación no es aplicable a las normas que otorgan a las autoridades públicas poderes para requerir información de los individuos; el entero objetivo de esta normativa es permitir a las autoridades obtener la información necesaria para cumplir sus funciones frente a las personas que disponen de la información por sus especiales conocimientos»; vid. «The element...», cit., pág. 13. 
No obstante, la ausencia de previsión acerca del derecho a la no autoinculpación no ha impedido que el TJUE en dos sentencias de 18 de octubre de 1989, Orkem ${ }^{36}$ y Solvay ${ }^{37}$, matice el deber de los particulares de entregar la información requerida por la Administración de la que derivaría su inculpación.

Puede decirse al respecto que, a diferencia de lo que acontecía con el derecho a la confidencialidad de la correspondencia entre abogado y cliente, el TJUE no encuentra que el derecho a la no autoinculpación esté reconocido en los ordenamientos de todos los Estados miembros:

«Con carácter general, los ordenamientos jurídicos de los Estados miembros únicamente reconocen el derecho de no declarar contra sí mismo a la persona física acusada de infracción en el marco de un proceso penal. Por consiguiente, el análisis comparativo de los derechos nacionales no permite llegar a la conclusión de que exista, como común a los derechos de los Estados miembros, tal principio a favor de las personas jurídicas y en el ámbito de las infracciones de naturaleza económica, concretamente en materia de Derecho sobre la Competencia» ${ }^{38}$.

No obstante y pese a todo ello, el TJUE vincula el derecho a la no autoinculpación con el derecho de defensa, que es principio fundamental del ordenamiento jurídico comunitario ${ }^{39}$. Así, a la Administración le incumbe reunir las pruebas acreditativas de la infracción cometida por la empresa, por lo que implicaría vulnerar el derecho de defensa de ésta obligarla a entregar información de la que pudiera derivarse su inculpación. Afirma, en este sentido, lo siguiente el TJUE:

«Aunque para preservar la eficacia de los apartados 2 y 5 del artículo 11 del Reglamento 17 la Comisión tenga la potestad de obligar a la empresa a que facilite toda la información necesaria relacionada con los hechos de los que pueda tener conocimiento y a que le presente, si fue-

\footnotetext{
36 STJCE de 19 de octubre de 1989, asunto 374/87.

37 STJCE de 19 de octubre de 1989 , asunto $27 / 88$.

38 STJCE Orkem.

${ }^{39}$ Así, en este sentido lo proclamó la STJCE de 9 de noviembre de 1983, asunto 322/82, Michelin. Igualmente, vid. B. VILA Costa, "Los derechos de defensa en el Derecho Comunitario», RIE, vol. 17, núm. 2, 1990, págs. 499 y ss.; A. MENÉNDEZ, «Los derechos del administrado en los procedimientos de aplicación del Derecho de la Competencia», REDA, núm. 7, 1993, págs. 5 y ss.; J. M. TRAYTER JimÉNEZ, La defensa de las empresas frente a las sanciones de la Administración europea, Bosch, 1988, págs. 31 y ss.
} 
ra preciso, los documentos correspondientes que obren en su poder, incluso si los mismos pueden servir para probar contra ella o contra cualquier otra empresa la existencia de una conducta contraria a la competencia, la referida institución no puede, mediante una decisión de solicitud de información, vulnerar el derecho de defensa reconocido a la empresa.

Así pues, la Comisión no puede imponer a la empresa la obligación de dar respuestas que impliquen admitir la existencia de una infracción cuya prueba incumbe a la Comisión» ${ }^{40}$.

A partir de este pronunciamiento, las empresas pueden rechazar contestar un requerimiento de entrega de información solicitado por la Comisión si consideran que ello podría suponer su autoinculpación. La impugnación de este requerimiento ante el TG genera que la jurisdicción comunitaria sea competente para revisar la información exigida y anular la correspondiente decisión en caso de que la Comisión pretenda la entrega de la información que genere la autoinculpación de la empresa por vulnerar el derecho de defensa. En este sentido, en la STJUE Orkem el Tribunal procede a analizar detalladamente las informaciones que la Comisión obliga a remitir. De este modo, señala que

«la letra c) de la subpregunta 1, cuyo objeto es obtener precisiones sobre "toda gestión o medida concertada que pueda haber sido considerada o adoptada para sostener iniciativas en materia de precios", supone obligar a la demandante a confesar su participación en un acuerdo que tiene por objeto fijar los precios de venta, apto para impedir o restringir el juego de la competencia, o a declarar haber tenido intención de conseguir dicho objetivo.

La misma observación se impone en lo relativo a las preguntas 1 y 2 sub III sobre cuotas, objetivos o repartos entre los productores. Al exigir la comunicación de las "modalidades de cualquier sistema o método que haya permitido asignar objetivos de venta o cuotas a los participantes" y la descripción de "cualquier método que haya permitido controlar cada año la observancia de cualquier sistema de objetivos expresados en volumen de cuo-

40 STJCE Orkem. 
tas", la Comisión se propuso conducir a la demandante a confesar su participación en un acuerdo destinado a limitar o a controlar la producción o las ventas o a repartirse los mercados.

Es preciso llegar a la conclusión de que la Comisión, al obligar, mediante las preguntas (...) de la solicitud de información, a la empresa destinataria a confesar una infracción del artículo 85 del Tratado CEE, ha vulnerado el derecho de defensa del demandante» ${ }^{41}$.

En consecuencia, puede afirmarse respecto al conflicto que puede originarse derivado de la potestad que tiene la Comisión para obligar a la empresa a facilitar toda la información necesaria relacionada con hechos de los que pueda tener conocimiento y a que le presente, si fuera preciso, los documentos correspondientes que obren en su poder, aun cuando éstos puedan servir para probar contra ella o contra cualquier otra empresa la existencia de una conducta contraria a la competencia, frente al derecho a no autoinculparse que tienen las empresas, dos conclusiones fundamentales.

En primer lugar, la jurisprudencia comunitaria reconoce un derecho a las empresas a guardar silencio, si bien este derecho no es absoluto, ya que si no constituiría un obstáculo injustificado para el cumplimiento por parte de la Comisión de la misión de velar por el respeto de las normas de competencia en el mercado común y, además, excedería de lo que resulta necesario para preservar los derechos de defensa de las empresas.

Además, en segundo lugar, el derecho a guardar silencio sólo puede reconocerse a una empresa destinataria de una decisión de solicitud de información en el sentido señalado por el Reglamento 1/2003, en la medida en que se viera obligada a dar respuestas «que implicaran ad-

41 Ibidem. Cabe hacer mención a que el TJCE, en su sentencia de 10 de noviembre de 1993, asunto C-60/92, Otto, ha considerado que el reconocimiento del derecho de las empresas a la no autoinculpación en el procedimiento tramitado por la Comisión no es extrapolable a un proceso civil nacional de aplicación del Derecho comunitario de la Competencia. Éste se ha de desarrollar de acuerdo con las normas procesales nacionales que disponen las medidas oportunas para satisfacer los derechos de defensa de las empresas. No obstante, el TJCE insiste sobremanera en que el supuesto viene caracterizado por tratarse de un proceso civil, que concierne exclusivamente a las relaciones privadas entre particulares. Como indica el TJCE en el asunto Orkem, el derecho a la no autoinculpación «es esencialmente destinado a proteger al particular contra las medidas de instrucción ordenadas por la autoridad pública para inducir a admitir la existencia de comportamientos susceptibles de sanción penal o ad-

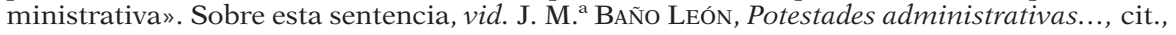
pág. 200. 
mitir la existencia de la infracción cuya existencia debe ser probada por la Comisión» ${ }^{42}$.

En la actualidad debe señalarse que el artículo 48.2 de la Carta de Derechos Fundamentales de la UE recoge de forma expresa el derecho de defensa, dentro del cual se enmarca, como acabo de examinar, el derecho a no autoinculparse.

Por otro lado, nuestra CE recoge de forma expresa en su artículo 24.2 los derechos a no declarar contra sí mismos y a no confesarse culpables, que se encuentran estrechamente relacionados con los derechos de defensa y a la presunción de inocencia, de los que constituye una manifestación concreta. En particular, como ha afirmado el TC, estos derechos

«son garantías o derechos instrumentales del genérico derecho de defensa, al que prestan cobertura en su manifestación pasiva, esto es, la que se ejerce precisamente con la inactividad del sujeto sobre el que recae o puede recaer una imputación, quien, en consecuencia, puede optar por defenderse en el proceso en la forma que estime más conveniente para sus intereses, sin que en ningún caso pueda ser forzado o inducido, bajo constricción o compulsión alguna, a declarar contra sí mismo o a confesarse culpable» ${ }^{43}$.

Pues bien, por lo que respecta a nuestro ámbito de investigación, se trata de analizar el alcance de esta garantía prevista en el artículo 24.2 CE en la LDC.

En primer lugar, debe señalarse a este respecto que el derecho a no declarar contra sí mismo rige en todo procedimiento administrativo de carácter sancionador que pueda tener consecuencias desfavorables por aplicación de la jurisprudencia constitucional vertida en torno al artículo $24.2 \mathrm{CE}^{44}$. Por tanto, puede afirmarse que la exclusión de este de-

42 STPI de 20 de febrero de 2001, asunto T-112/98, Mannesmannrohen-Werke AG contra Comisión.

43 SSTC 197/1995, de 21 de diciembre; 161/1997, de 2 de octubre; 229/1999, de 13 de diciembre; 67/2001, de 17 de marzo; 18/2005, de 1 de febrero.

${ }_{44}$ Así lo ha reconocido la jurisprudencia del TC, que en su STC 197/1995, de 21 de diciembre, se pronunció sobre la aplicación al procedimiento administrativo sancionador del derecho del acusado a no declarar contra sí mismo. Se trataba de saber si el artículo 72.3 de la Ley sobre Tráfico y Seguridad Vial, que obliga al propietario del vehículo a «identificar al conductor responsable de la infracción», era contrario al derecho fundamental del artículo 24.2 CE. El TC recuerda su conocida doctrina sobre la vigencia de los derechos de defensa del artículo $24 \mathrm{CE}$ en el procedimiento administrativo sancionador y subraya que también en él «la carga de la prueba de los hechos constitutivos en la infracción vincula a la Administración, que concentra las funciones de acusador y decidor, sin que el sujeto pasivo de la ac- 
recho del procedimiento de defensa de la competencia carece de fundamentos en nuestro ordenamiento jurídico.

El contenido garantizado de la LDC consiste en el derecho a no declarar o contestar a las preguntas que, a juicio del sujeto pasivo de una inspección, puedan suponerle una medida aflictiva. Parece aconsejable que se invoque el derecho al silencio para excluir la imputación de obstrucción o falta de colaboración con las funciones de la CNC y, consiguientemente, la aplicación del artículo 62.2.c) de la LDC, que establece como infracción administrativa leve «no haber suministrado a la Comisión Nacional de la Competencia la información requerida por ésta o haber suministrado información incompleta, incorrecta, engañosa o falsa».

No puede decirse, como ha señalado el TC en su sentencia 18/2005, de 1 de febrero, que se restrinja el contenido de la garantía del artículo $24.2 \mathrm{CE}$ cuando la ley exige un deber de colaboración, a cuyo fin permite la imposición de la sanción coercitiva prevista por la norma legal correspondiente. Esta limitación es, por tanto, conforme con la $\mathrm{CE}$, en cuanto no priva del contenido al derecho y es justificable en atención a la finalidad de prohibir el abuso del derecho por parte del particular sometido a una investigación o inspección.

En consecuencia, aplicando esta doctrina al Derecho de la Competencia, concretamente la LDC, podemos afirmar que cuando esta norma establece la imposición de sanciones a las empresas que no cumplan con el deber de suministrar la información requerida por la CNC es perfectamente constitucional y los sujetos pasivos de las inspecciones no podrán esgrimir el derecho a no declarar contra sí mismos en el curso de este procedimiento administrativo. De esta forma, da la sensación que el TC, a diferencia de lo que ocurre en el ámbito comunitario, restringe el ámbito de aplicación de este derecho cuando nos encontramos ante un procedimiento administrativo, a diferencia de lo que ocurre cuando se trata de un proceso penal. Así, parece condicionarse

tuación sancionadora esté obligado a declarar contra sí mismo». Daba la impresión que tras esta declaración general la conclusión debería ser estimatoria de las cuestiones de inconstitucionalidad planteadas, cuando el titular del vehículo hubiera sido precisamente quien lo condujera en el momento de la infracción. Sin embargo, el TC, con un planteamiento formalista que elude el hecho de que el artículo 24.2 CE reconoce no sólo el derecho a no declararse culpable, sino el derecho a no declarar contra sí mismo, establece que «el artículo 72.3 de la LTSV no conmina al titular del vehículo a declarar sobre la supuesta infracción de tráfico, sino, simplemente, a comunicar a la Administración el nombre del conductor del vehículo, de modo que, aunque concurran en una misma persona las circunstancias de conductor y propietario del vehículo, a éste no se le impone el deber ni de efectuar declaración alguna sobre la infracción, ni de autoinculparse de la misma, sino únicamente el de comunicar la identidad de quien realizaba la conducción». 
la delimitación de este derecho por la aplicación del principio de eficacia de las Administraciones públicas, reconocido en el artículo $103.1 \mathrm{CE}^{45}$.

V. LÍMITES AL USO Y CESIÓN DE LA INFORMACIÓN OBTENIDA MEDIANTE LOS REQUERIMIENTOS DE INFORMACIÓN: EN ESPECIAL, LA CONFIDENCIALIDAD DE DETERMINADA INFORMACIÓN

El artículo 27.6 LCNMC establece que los datos e informaciones obtenidos en el curso de las investigaciones que desarrollen las autoridades de competencia sólo podrán ser utilizados por éstas para las finalidades previstas en la legislación de competencia. Debe entenderse que esta previsión se aplica también a los requerimientos de información previstos en el artículo 28 LCNMC, que en su apartado segundo establece que «los datos e informaciones obtenidos por la Comisión Nacional de los Mercados y la Competencia en el desempeño de sus funciones, con la excepción de los previstos por las letras c), d), e) y f) del apartado 1 del artículo 5 de esta Ley, que tengan carácter confidencial por tratarse de materias protegidas por el secreto comercial, industrial o estadístico, sólo podrán ser cedidos al Ministerio competente, a las Comunidades Autónomas, a la Comisión Europea y a las autoridades de otros Estados miembros de la Unión Europea en el ámbito de sus competencias, así como a los tribunales en los procesos judiciales correspondientes».

Así, por un lado, se permite que la información obtenida por la CNMC mediante los requerimientos de información pueda ser empleada por las autoridades de competencia para el cumplimiento de sus fines. Por otro lado y como consecuencia de la naturaleza de la información que puede ser cedida, especialmente la que pueda tener carácter confidencial, se van a prever una serie de cautelas respecto de la misma que serán objeto de examen en los próximos epígrafes.

1. Derecho a la confidencialidad en relación con los documentos objeto de los requerimientos de información

La diversidad e importancia de las informaciones que pueden obtener las autoridades de competencia durante el transcurso de sus investigaciones imponen, como ya se ha advertido, un especial deber de

45 Sobre este punto, vid. E. Gómez-Reino y CARnota, «Las facultades de...», cit., págs. 33 y ss.; J. M. ${ }^{a}$ BAÑo LEÓN, Potestades administrativas..., cit., págs. 190 y ss. 
sigilo en los inspectores, debido a los graves perjuicios que el mal uso de la misma puede originar para las empresas afectadas por la inspección ${ }^{46}$.

De hecho, en distintos procedimientos en los que son parte competidores de la empresa denunciada, el acceso a la documentación requerida podría causar perjuicios irreparables en el mercado a la misma. Debido a que para examinar las conductas que pueden vulnerar la legislación de competencia se exige con carácter general un análisis exhaustivo de la estrategia empresarial, así como del comportamiento interno, resulta lógico que el legislador haya mostrado una cierta preocupación y, en consecuencia, haya establecido garantías que armonicen el deber general de colaboración que tienen las empresas inspeccionadas con las necesidades que exige el secreto de determinados intereses comerciales de las mismas ${ }^{47}$.

En este sentido, y como se ha examinado anteriormente, el Reglamento 1/2003 recoge el deber general de secreto, concretamente su artículo 28.2, al prever que «la Comisión y las autoridades de la competencia de los Estados miembros, así como sus funcionarios, agentes y demás personas que trabajen bajo la supervisión de esas autoridades, y también los funcionarios y agentes de las otras autoridades de los Estados miembros, estarán obligados a no divulgar la información que hayan recopilado o intercambiado en la aplicación del presente Re-

46 Así lo ha señalado el TJUE en su sentencia de 12 de noviembre de 2014, asunto Altman y otros c. Bundesanstalt fur Finanzdiienstleistungsaufsicht (C-140/13), en la que se destaca que "el funcionamiento eficaz del sistema de control de la actividad de las empresas de inversión, basado en una supervisión ejercida en el interior de un Estado miembro y en el intercambio de información entre las autoridades de varios Estados miembros (...), requiere que tanto las empresas supervisadas como las autoridades competentes puedan estar seguras de que la información confidencial proporcionada conservará en principio su carácter confidencial».

47 Los mecanismos de protección de la confidencialidad revisten una importancia especial en los procedimientos de defensa de la competencia, como ha acertado en destacar M. Pedraz Calvo, "La confidencialidad del expediente administrativo», en Anuario de la Competencia 1997, Marcial Pons-ICO, Madrid, 1998, págs. 175 y ss.

Existen diversos motivos que justifican lo anterior. De una parte, en esta materia es frecuente que se discuta sobre informaciones constitutivas de secreto de negocios, además de manera prolija y detallada. Ejemplos de otras informaciones susceptibles de provocar un daño injusto en su divulgación son, asimismo, la identidad de operadores en caso de riesgo de represalia; la especificación de determinados detalles de compromisos o condiciones, tales como la fecha límite para la venta de un negocio por exigencia impuesta por la autoridad; los informes de abogados, por razón de protección de los derechos de defensa; incluso la incontrolada divulgación de la propia existencia del procedimiento de defensa de la competencia es susceptible de provocar daños injustos, lo que requiere y exige de una adecuada protección de este tipo de información. Sobre este punto, vid. M. ARAUJo, «El tratamiento confidencial de determinada información», en La modernización del Derecho de la Competencia (dirs. S. Martínez Lage y A. Petitbó Juan), Colección Derecho, Fundación Rafael del Pino, Madrid, 2005, págs. 171 y ss.; V. KoraH, Cases \& Material son EC Competition Law, Hart Publishing, Oxford, 2007, págs. 239 y ss. 
glamento y que, por su naturaleza, esté amparada por el secreto profesional. Esta obligación se aplicará asimismo a todos los representantes de los Estados miembros que asistan a las reuniones del Comité Consultivo conforme a lo dispuesto en el artículo $14{ }^{48}$.

Por otro lado, se prevé en el Reglamento (CE) 773/2004 de la Comisión, de 7 de abril de 2004, relativo al desarrollo de los procedimientos de la Comisión con arreglo a los artículos 81 y 82 del Tratado CE (en adelante, Reglamento 773/2004), el tratamiento de información confidencial, previsión de suma importancia en este ámbito ya que existe determinada información de las empresas sujetas a inspección que sólo puede y debe ser conocida por las autoridades de competencia, pero que debe resultar inasequible a los competidores por el perjuicio económico que ello puede suponer. En este sentido, lo prevé el artículo 16, reiterando en su apartado primero la protección de la información confidencial al prescribir que «la Comisión no comunicará ni dará acceso a la información, incluidos los documentos, si contiene secretos comerciales u otro tipo de información confidencial sobre cualquier persona»; añadiendo en su apartado segundo que «toda persona que formule sus observaciones con arreglo al apartado 1 del artículo 6, al apartado 1 del artículo 7, al apartado 2 del artículo 10 o a los apartados 1 y 3 del artículo 13 o que presente ulteriormente información adicional a la Comisión en el curso del mismo procedimiento, deberá indicar con claridad los elementos que considere confidenciales, exponiendo sus razones, y facilitar una versión separada no confidencial en el plazo establecido por la Comisión para que formule sus observaciones».

En parecidos términos lo recoge la LDC en su artículo 43.1, disponiendo lo siguiente: «todos lo que tomen parte en la tramitación de expedientes previstos en esta Ley o que conozcan tales expedientes por razón de profesión, cargo o intervención como parte, deberán guardar secreto sobre los hechos de que hayan tenido conocimiento a través de ellos y de cuantas informaciones de naturaleza confidencial hayan tenido conocimiento en el ejercicio de sus cargos, incluso después de cesar en sus funciones».

Este precepto se encuentra íntimamente ligado al artículo 42 LDC, que regula el tratamiento confidencial de determinada información a

48 Este deber de secreto ha sido recogido, igualmente, en la nueva LDC, que dispone en su artículo 43 lo siguiente: «1. Todos los que tomen parte en la tramitación de expedientes previstos en esta Ley o que conozcan tales expedientes por razón de profesión, cargo o intervención como parte, deberán guardar secreto sobre los hechos de que hayan tenido conocimiento a través de ellos y de cuantas informaciones de naturaleza confidencial hayan tenido conocimiento en el ejercicio de sus cargos, incluso después de cesar en sus funciones. 2. Sin perjuicio de las responsabilidades penales y civiles que pudieran corresponder, la violación del deber de secreto se considerará siempre falta disciplinaria muy grave». 
la que puedan tener acceso tanto los funcionarios como los interesados en el expediente administrativo, que crea una obligación de no divulgar la citada información, como examinaré en los epígrafes siguientes.

\section{A) La delimitación del objeto de la confidencialidad}

El Derecho de la Competencia ha conferido una mayor amplitud en su intento de delimitar el derecho a la confidencialidad de determinados documentos que ha ido más allá de lo referido a los secretos comerciales o de negocios de las empresas. Ello obedece a la necesidad de proteger determinada información que tienen las empresas, de tal modo que la divulgación de la misma podría dañar seriamente y de forma significativa a su estructura y funcionamiento.

De este modo, la confidencialidad de determinada información que pueda afectar al secreto comercial, estadístico o industrial de las empresas constituye un límite importante a la transparencia con la que deben desarrollar sus funciones las autoridades de competencia, y que, por tanto, debe ser objeto de especial protección por las mismas. De la misma forma, la declaración de determinada información como confidencial supondrá un límite a la regla general de acceso al expediente administrativo que establece la legislación vigente y que ha sido ratificado por la jurisprudencia. El Reglamento 1049/2001 parte del derecho general de acceso al expediente, si bien éste podrá limitarse de acuerdo al artículo 4.2 cuando la divulgación conlleve un claro perjuicio para la protección de los intereses comerciales de una persona física o jurídica, incluida la propiedad intelectual, o cuando el objetivo de las actuaciones de inspección e investigación revista un interés público superior.

Del mismo modo, tanto la legislación de competencia como la reciente Ley 19/2013, de 9 de diciembre, de transparencia, acceso a la información pública y buen gobierno, que es de aplicación a la CNMC, parten igualmente de un derecho de acceso general, si bien éste se puede ver limitado por determinados motivos establecidos en su artículo $14^{49}$, entre los que se encuentran, entre otros, las funciones administrativas de vigilancia, inspección y control, así como los intereses económicos y comerciales, el secreto profesional y la propiedad intelectual e industrial. Estableciendo en su apartado segundo que «la aplicación de los límites

49 Sobre este punto, vid. J. GuILlÉn CARAMÉs, «Transparencia y acceso a la información pública en el Derecho de la Competencia», en Régimen jurídico de la transparencia en el sector público (coords. J. VAlero TorriJo y M. FERnández SAlmerón), Aranzadi-Thomson Reuters, 2014, págs. 669 y ss. 
será justificada y proporcionada a su objeto y finalidad de protección y atenderá a las circunstancias del caso concreto, especialmente a la concurrencia de un interés público o privado superior que justifique el acceso».

Queda puesta de manifiesto la relevancia que el ordenamiento jurídico otorga a determinados documentos empresariales.

En líneas generales y sin ánimo de exhaustividad, el objeto de la confidencialidad recae sobre determinados documentos de naturaleza empresarial cuya divulgación podría causar un grave perjuicio a las empresas. Como ejemplo de dicha información que puede considerarse como secreto comercial cabe citar la información técnica y/o financiera relativa a los conocimientos técnicos de una empresa, los métodos de evaluación de costes, los secretos y procesos de producción, las fuentes de suministro, las cantidades producidas y vendidas, las cuotas de mercado, los ficheros de clientes y distribuidores, la estrategia comercial, la estructura de costes y precios y la estrategia de ventas ${ }^{50}$.

No obstante, la legislación de competencia otorga un amplio margen de discrecionalidad a la CNMC para acordar la confidencialidad de datos y documentos, si bien dicho margen de apreciación se encuentra limitado por el deber de motivación y el principio de proporcionalidad, tal y como he señalado anteriormente. Al respecto, la CNMC ha señalado en su resolución Bombas Caprari lo siguiente:

«a la hora de determinar qué datos son confidenciales, en línea con la práctica de la CNC, la Dirección de Investigación ha ponderado los principios de transparencia y de deber de secreto de aquellas informaciones que estén protegidas por el secreto comercial (...), utilizando con carácter interpretativo la definición de secretos comerciales de la Comunicación de la Comisión Europea de acceso al expediente. Así, dicha comunicación, en su apartado 3.2.1, entiende que:

Cuando la divulgación de información sobre la actividad económica de una empresa pueda causarle un perjuicio. Como ejemplo de dicha información que puede considerarse como secreto comercial cabe citar la información técnica y/o financiera relativa a los conocimien-

50 Vid. sobre este punto el Antitrust Manual of Procedures, publicado por la DG COMP (2012). Igualmente, vid. M. M. ${ }^{a}$ RAZQuin LizARRAGA, La confidencialidad de los datos empresariales en poder de las Administraciones Públicas (Unión Europea y España), Iustel, 2013, págs. 125 y ss. 
tos técnicos de una empresa, los métodos de evaluación de costes, los secretos y procesos de producción, las fuentes de suministro, las cantidades producidas y vendidas, las cuotas de mercado, los ficheros de clientes y distribuidores, la estrategia comercial, la estructura de costes y precios y la estrategia de ventas grave, dicha información tendrá el carácter de secreto comercial.

Teniendo en cuenta todo ello, la Dirección de Investigación declaró confidencial aquellos documentos que pudieran contener datos que no debieran trascender públicamente por tratarse de secretos comerciales y cuya revelación pudiera causar un perjuicio a la empresa» ${ }^{51}$.

\section{B) El tratamiento de la información confidencial}

La confidencialidad de determinada información que podría ser objeto de un requerimiento de información por parte de la CNMC se configura como un interés legítimo de las partes implicadas en los procedimientos sancionadores de defensa de la competencia, cuyo reconocimiento corresponde a la CNMC, previa resolución debidamente motivada en la que se establezca la concurrencia de los presupuestos para su aplicación ${ }^{52}$.

La LDC establece en su artículo 42 el tratamiento que debe darse a la información confidencial, señalando que «en cualquier momento del procedimiento se podrá ordenar, de oficio o a instancia de parte, que se mantengan secretos los datos o documentos que consideren confidenciales, formando con ellos pieza separada, sin perjuicio de lo establecido en el artículo 18 de la presente Ley y en el Reglamento (CE) n. ${ }^{\circ}$ 1/2003 del Consejo, de 16 de diciembre de 2002, relativo a la aplicación de las normas sobre competencia previstas en los artículos 81 y 82 del Tratado. En todo caso, se formará pieza separada especial de carácter confidencial con la información remitida por la Comisión Europea en respuesta a la remisión del borrador de resolución de la Comisión Nacional de la Competencia previsto en el artículo 11.4 del Reglamento $1 / 2004 »^{53}$.

51 Resolución de 24 de junio de 2010 (Expte. R/0042/10).

52 Vid. J. Martín PASTOR, "Artículo 42», op. cit., pág. 803.

53 Artículo 18 de la LDC, que lleva como título Colaboración de la Comisión Nacional de la Competencia con Autoridades Nacionales de Competencia de otros Estados miembros y la Comisión Europea: "Al objeto de aplicar los artículos 81 y 82 del Tratado de la Comunidad Europea, la Comisión Nacional de la Competencia podrá intercambiar con la Comisión Europea y con las Autoridades Nacionales de Competencia de otros Estados miembros y utilizar 
En principio, se puede solicitar la declaración de confidencialidad en cualquier momento del procedimiento, ya sea de oficio, ya sea a instancia de parte interesada. Así lo ha aplicado la CNMC al señalar en su resolución Grafoplas lo siguiente:

«conforme con el artículo 42 LDC las declaraciones de confidencialidad se podrán realizar en cualquier momento del procedimiento, siendo práctica habitual de la DI resolverlas en un momento procesal anterior a la imputación formal realizada en el $\mathrm{PCH}$, precisamente para que a quienes les ha sido incoado un procedimiento sancionador puedan ir teniendo conocimiento de toda la documentación en la que, eventualmente, pueda fundarse su imputación, lo que no viene a ser sino una garantía del derecho de defensa que le asiste; y por otro lado, que no existe peligro de divulgación de la mencionada información, ya que ésta no puede ser conocida por terceros ajenos al expediente y sobre los interesados en este expediente pesa el deber de secreto a que hace referencia el artículo 43 de a $\mathrm{LDC}{ }^{54}$.

A su vez, cuando una persona aporte documentos a la CNMC y solicite la confidencialidad de determinada información tiene el deber de motivarlo suficientemente ante la autoridad de competencia, y deberá presentar, asimismo, una versión no confidencial de los mismos, tal y como prevé el artículo 20 del RD 261/2008.

como medio de prueba todo elemento de hecho o de derecho, incluida la información confidencial, en los términos previstos en la normativa comunitaria».

A su vez, el artículo 11.4 del Reglamento 1/2003 señala lo siguiente: «A más tardar 30 días antes de la adopción de una decisión por la que se ordene la cesación de una infracción por la que se acepten compromisos o por la que se retire la cobertura de un reglamento de exención por categorías, las autoridades competentes de los Estados miembros informarán de ello a la Comisión. A tal efecto, le proporcionarán una exposición resumida del asunto y del texto de la decisión prevista, o en ausencia de ésta, cualquier otro documento en el que se indique la línea de acción propuesta. Esta información podrá ponerse también a disposición de las autoridades de competencia de los demás Estados miembros. A instancias de la Comisión la autoridad de competencia encargada del asunto deberá poner a disposición de la Comisión otros documentos que se hallen en su poder y que sean necesarios para evaluar el asunto. La información facilitada a la Comisión podrá ponerse a disposición de las autoridades de competencia de los demás Estados miembros. Las autoridades nacionales de competencia podrán asimismo intercambiarse la información necesaria para evaluar el asunto que estén instruyendo al amparo de los artículos 81 y 82 del Tratado».

54 Resolución de 22 de junio de 2011 (Expte. R/0070/10). 
C) La prohibición de la utilización de la información para fines distintos a los establecidos en la legislación de competencia

El Reglamento 1/2003, al atribuir potestades a la Comisión para la realización de actuaciones inspectoras, establece una medida general de garantía para los particulares consistente en que la información recabada en su ejercicio sólo podrá ser utilizada para el fin que justificó su solicitud. Dispone, en efecto, el artículo 28.1 de la citada norma que «sin perjuicio de los artículos 12 y 15, la información recopilada en aplicación de los artículos 17 a 22 sólo podrá utilizarse para el fin para el que haya sido recabada».

El TJUE ha señalado al respecto que

«del artículo (...) se desprende, en efecto, que la información obtenida durante las verificaciones no debe utilizarse para fines distintos de los indicados en el mandato de verificación o en la decisión de verificación. Dicha exigencia debe preservar, además el secreto profesional (...), el derecho de defensa de las empresas ${ }^{55}$.

Esta garantía supone el contrapunto al otorgamiento de amplias potestades de inspección a los inspectores de competencia. Éstas pueden suponer un menoscabo a los derechos de las empresas y, en consecuencia, la información obtenida únicamente debe poder ser empleada para el fin que la justifica ${ }^{56}$.

En concreto, se ha planteado el conflicto de la posible utilización de la información obtenida por la Comisión por parte de las autoridades nacionales, que, como se ha visto, pueden tener conocimiento de la misma a través de distintas vías. Las autoridades nacionales, ya sea para la aplicación del Derecho nacional o del Derecho comunitario de la Competencia, pueden pretender hacer uso de la información que les remite la Comisión derivada del ejercicio de las actuaciones inspectoras ${ }^{57}$.

Esta cuestión ha sido analizada por el TJUE en la sentencia de 16 de julio de 1992, resolviendo una cuestión prejudicial formulada por el

55 STJCE de 17 de octubre de 1989, asunto 85/87, Dow Benelux.

56 Vid. Ll. CASES, Derecho administrativo de defensa de la comptencia, Marcial Pons-ICO, Madrid, 1995, pág. 160; T. K. GiannoKopoulos, Safeguarding companies in competition and antidumping/anti-sybsidies proceedings, Kluwer Law International, 2004, págs. 111 y ss.

57 Sobre este particular, vid. D. G. Goyder, EC Competition Law, Oxford University Press, 2003, págs. 510 y ss.; VAN BAEL \& BELLIS, Competition Law of the European Community, Kluwer Law International, The Hague, 2005, págs.1079 y ss. 
TDC español ${ }^{58}$. La autoridad de competencia española sostenía que las autoridades nacionales pueden utilizar la información obtenida por la Comisión en ejercicio de las potestades que le otorga el Reglamento $17 / 62$ (en la actualidad, Reglamento 1/2003), tanto para aplicar las normas sobre competencia comunitarias como las nacionales, en tanto que el objetivo y la finalidad de ambas son idénticos. Por su lado, la Comisión mantenía que las autoridades nacionales podían utilizar esa información sólo para aplicar el Derecho comunitario de la Competencia, que era lo que había justificado su obtención. Las empresas afectadas, finalmente, entendían que las autoridades nacionales no podían en ningún caso utilizar la referida información.

El TJCE pone de relieve que el Reglamento comunitario regula el procedimiento que tramita la Comisión y no el que pueden seguir las autoridades nacionales. Por este motivo,

«no es pertinente la distinción que hace la Comisión entre los casos en que las autoridades nacionales utilicen las informaciones mencionadas para aplicar el Derecho Comunitario y los casos en que estas autoridades actúen en aplicación del Derecho de la Competencia nacional. En ambos casos, en efecto, el procedimiento que tramitan las autoridades nacionales es distinto del que se sigue ante la Comisión, y la recogida de pruebas por parte de dichas autoridades se rige por las normas que establece el Derecho nacional, sin perjuicio del respeto al Derecho Comunitario. Incluso en el caso de que apliquen las disposiciones materiales (...) las autoridades nacionales están obligadas a aplicarlas siguiendo sus normas nacionales» ${ }^{59}$.

Por lo tanto, para el TJUE resulta esencial limitar que el resultado del ejercicio de la potestad administrativa sea operativo en el procedimiento en que aquélla se inserta y, por ello, se justifica. Las potestades administrativas y, claro está, su resultado son indisociables del procedimiento en que la norma las establece. Lo contrario, emplear el resultado de las potestades administrativas en el marco de un procedimiento en que éstas no se encuentran justificadas, sería opuesto a los derechos de los afectados. Por ello, en tanto que la legislación de competencia comunitaria pretende proporcionar instrumentos a la Comi-

58 STJCE de 16 de julio de 1992, asunto C-67/91, Asociación Española de Banca (AEB).

59 Ibidem. 
sión para ejercitar sus facultades, «el valor probatorio de las informaciones comunicadas de esta manera y las condiciones en que pueden invocarse en contra de las empresas vienen establecidos, en consecuencia, por el derecho comunitario y quedan limitados exclusivamente a los procedimientos regulados por el Reglamento 17. El fin de la solicitud de información no es proporcionar elementos de prueba que se rigen por el Derecho nacional» ${ }^{60}$.

Cuestión distinta es el uso que pueda hacerse de la información recogida por la Comisión Europea en el marco de una inspección comunitaria en el marco de un procedimiento judicial nacional. Se plantea entonces la problemática de si la Comisión tiene la obligación de prohibir a las empresas a las que esta institución ha comunicado determinados documentos del procedimiento administrativo que los puedan aportar en un procedimiento judicial nacional. Se trata de un claro supuesto de cooperación entre la Comisión y los órganos jurisdiccionales nacionales, en la medida en que estos últimos, gracias a que una de las partes en el proceso judicial ha aportado dichos documentos, podrán ser empleados en el seno de su apreciación de la existencia de posibles vulneraciones de los artículos 101 y 102 del TFUE ${ }^{61}$.

Ha sido el antiguo TPI el que entró a resolver esta controversia en el asunto Postbank contra Comisión, de 18 de septiembre de $1996^{62}$, que, por cierto, se sustanció en el marco del antiguo Reglamento 17, estableciendo la posibilidad de dicha cooperación. Dice así el TPI:

«Ahora bien, contrariamente a lo que sostiene la parte demandante, esta colaboración entre la Comisión y los Jueces nacionales escapa al ámbito de aplicación del re-

60 Ibidem. Sobre esta sentencia, vid. E. LlopIS REYNA, "Intercambio de información entre Administraciones Públicas y derechos de defensa», REDA, núm. 83, 1994, págs. 477 y ss.; A. MenÉnDEZ, «Los derechos del administrado en los procedimientos de aplicación del Derecho de la Competencia», REDA, núm. 77, 1993, págs. 5 y ss.; M. REBollo PUIG, «Potestades inspectoras y...», en La Comisión Nacional..., op. cit., págs. 768 y ss.

61 Debe recordarse que del artículo 10 del TCE se desprende el principio de cooperación leal que impone a las instituciones comunitarias, y sobre todo a la Comisión, el deber de prestar una asistencia activa a toda autoridad judicial nacional que conozca de posibles infracciones de una norma comunitaria. Como ha señalado el TJCE en su auto de 13 de julio de 1990, Zarweld y otros, dicha asistencia, que se presenta bajo diversas formas, puede «consistir, en su caso, en la comunicación a los jueces nacionales de documentos que las Instituciones han obtenido en el cumplimiento de sus funciones».

Por tanto, en el marco de un procedimiento de aplicación de las normas comunitarias sobre la competencia, este principio implica esencialmente, como se desprende de la jurisprudencia del TJCE (C-234/89, Delimitis, de 28 de febrero de 1991, y C-319/93, C-40/94 y C-224/94, Dijkstra y otros, de 12 de diciembre de 1995), que el juez nacional tiene derecho a informarse ante la Comisión sobre el estado de un procedimiento que haya podido iniciarse y a obtener de la citada institución los datos económicos y jurídicos que ésta pueda proporcionarle.

62 T-353/94. 
glamento n. ${ }^{\circ}$ 17. Dicho Reglamento sólo contempla las relaciones entre la Comisión y las autoridades de los Estados miembros a las que se refiere el artículo 88 del Tratado, que ejercen competencias paralelas a las de la Comisión. En efecto, (...) las autoridades nacionales a las que se refiere dicho Reglamento no incluyen en absoluto a los órganos jurisdiccionales nacionales que aplican los artículos 85 y 86 del Tratado en virtud de su efecto directo. (...) En consecuencia, no puede interpretarse que el mencionado apartado 1 del artículo 20 obligue a la Comisión a prohibir a las empresas que aporten documentos del procedimiento administrativo en el marco de un procedimiento judicial nacional».

En definitiva, como se deriva de la jurisprudencia comunitaria, no puede prohibirse el empleo de dicha información en el seno de un proceso judicial nacional, puesto que en un principio dicha prohibición tendría la función de garantizar la protección de las empresas que justificaran un interés a que no se divulgasen informaciones de carácter confidencial, y en particular secretos comerciales, comunicadas a la Comisión durante el procedimiento de inspección comunitaria. No obstante, la exigencia de dicha protección no puede prevalecer sobre el derecho de las empresas, que disponen de dichas informaciones, a defenderse en el marco de un procedimiento judicial nacional.

\section{En especial, la confidencialidad en los documentos afectados por el} derecho de defensa

En el ejercicio de sus facultades de investigación, los inspectores pueden pretender acceder a toda la información existente en la empresa, obviamente, siempre y cuando tenga relación con el objeto de la inspección. Ya sea en la práctica de una visita de inspección o en el requerimiento o solicitud de entrega de determinada información, los inspectores pueden requerir a la empresa que les muestre la información que consideren necesaria, en la que puede constar la documentación intercambiada entre la empresa y sus asesores jurídicos.

Frente a esta potestad, otra de las garantías que supone un contrapeso o límite a las amplias facultades inspectoras de las autoridades de competencia la constituye aquella que deriva del derecho a la confidencialidad de las comunicaciones de los abogados con sus clientes, y 
que se encuentra fundamentalmente dirigida a proteger el carácter confidencial de este tipo de información. Como ha destacado el TJUE,

«esta confidencialidad responde a la exigencia, cuya importancia es reconocida en el conjunto de Estados miembros, de que todo justiciable debe tener la oportunidad de dirigirse con total libertad a su abogado, cuya profesión misma comporta ofrecer, de forma independiente, consejos jurídicos a todos aquellos que lo necesitan» ${ }^{63}$.

El Reglamento 1/2003 no contiene ninguna limitación expresa relativa a la posible confidencialidad de la documentación intercambiada entre las empresas y sus abogados. Sin embargo, afirma el TJUE en la sentencia mencionada, que resulta esencial en esta cuestión, que ello

«no excluye la posibilidad de reconocer, bajo ciertas condiciones, el carácter confidencial de determinados documentos profesionales. En efecto, el derecho comunitario resulta de una interpenetración no sólo económica, sino también jurídica entre los Estados miembros, que ha de tener en cuenta los principios y concepciones comunes de los derechos de estos Estados en lo que concierne al respecto a la confidencialidad, en especial de determinadas comunicaciones entre los abogados y sus clientes».

Del examen de las diferentes previsiones legales de los Estados miembros relativas al carácter confidencial de este tipo de comunicaciones, el TJUE concluye que

«los derechos internos de los Estados miembros revelan (...) la existencia de criterios comunes en cuanto que protegen, en condiciones similares, la confidencialidad de la correspondencia entre abogados y clientes siempre y cuando, por un lado, se trate de correspondencia inter-

63 STJCE de 18 de mayo de 1982, asunto 155/79, AM \& S Europe. Sobre esta sentencia ha sido abundante la literatura jurídica vertida, entre la que pueden destacarse: J. UsHER, «Legal Professional privilege and confidentiality in EEC Competition Proceedings: the judgement of the European Court», JBL, 1982, págs. 398 y ss.; N. CONNOLLY, «Legal privilege in the European Communities after the AM \& S Case», ECLR, núm. 2, 1982, págs. 246 y ss.; T. CHRIsTOFOROU, "Protection of legal privilege in EEC Competition Law: the imperfections of a case», FILJ, vol. 3, 1985, págs. 5 y ss.; T. K. GiannaKopoulos, Safeguarding companies..., cit., págs. 78 y ss.; J. FAULL, "In-house lawyers and legal professional privilege: a problem revisited», www.europa.eu.int/comm/dg04. 
cambiada en el marco y con los fines del derecho a la defensa del cliente y, por otro, de abogados no ligados al cliente por un vínculo salarial» ${ }^{64}$.

Por lo que respecta al ordenamiento jurídico nacional, si bien la LDC no dice nada al respecto, la protección de la confidencialidad de las comunicaciones entre abogado y cliente ha sido reconocida por la jurisprudencia del TC, señalando que la intervención administrativa de la correspondencia entre el interno en un establecimiento penitenciario y su abogado debe ser judicialmente autorizada (SSTC 183/1994, de 20 de junio, y 58/1998, de 16 de marzo).

Del mismo modo, la CNMC ya había reconocido este derecho vinculándolo a los derechos de defensa del interesado en su resolución Pepsi Cola v Coca Cola, de 22 de julio de $2002^{65}$. Del mismo modo, en sus resoluciones más recientes (como, por ejemplo, Stanpa, de 3 de octubre de 2008) se aborda de lleno esta problemática, señalando que

«la protección de la confidencialidad en la relación abogado-cliente exige de la empresa un comportamiento activo, que comunique y razone adecuadamente ante la Dirección de Investigación los motivos por los que dicho documento se encuentra protegido y por los que el simple acceso al mismo para su análisis somero causaría indefensión al afectado».

Una de las cuestiones problemáticas de la protección de la confidencialidad de las comunicaciones entre el abogado y su cliente estriba en encontrar su encaje o fundamento en algún derecho fundamental y ver cómo actúa ante las intervenciones administrativas que encuentran su anclaje en la protección de intereses generales, en nuestro caso el orden público económico, que es el eje de la protección de las normas de competencia.

Sin poder entrar en detalle en este debate, pues excede del propósito de este trabajo, debe señalarse que algunos autores han defendido que la garantía de la confidencialidad de las comunicaciones entre abogado y cliente se fundamenta en que la citada garantía es un elemento indisoluble del derecho de defensa, en particular del derecho a la asistencia de un abogado y del derecho a la no autoinculpación. De este modo, la confidencialidad de estas comunicaciones encontraría

64 Igualmente, vid. STJUE $A k z o$, de 14 de septiembre de 2010 (C-550/07 P).

65 Expte. R/508/02. 
su fundamento constitucional en el artículo 24 de la CE, así como en el artículo 6 del $\mathrm{CEDH}^{66}$.

Pues bien, no cabe duda alguna del juego en este ámbito de los derechos de defensa. Y, en este sentido, el artículo 24.2, en su segundo párrafo, lo reconoce, remitiendo a la ley la regulación del derecho a guardar silencio sobre hechos presuntamente delictivos ${ }^{67}$.

El TC, en su sentencia 108/1984, de 26 de noviembre, ha señalado que el secreto profesional es un límite de las potestades administrativas de inspección. Dice así:

«El secreto profesional, es decir, el deber de secreto que se impone a determinadas personas, entre ellas los abogados, de lo que conocieren por razón de su profesión, viene reconocido expresamente por la Constitución (...) en su artículo 24.2 (...). Evidentemente, y a fortiori, tampoco existe el deber de declarar a la Administración por estos hechos. La Constitución consagra aquí lo que es tradición legislativa».

También se ha afirmado, como fundamento de la confidencialidad de este tipo de comunicaciones, el artículo 18.3 de la CE y el artículo 8 del CEDH, en el que el bien jurídico protegido por dichos preceptos es, a través de la imposición a todos del secreto, la libertad de las comunicaciones, cualquiera que sea el sistema empleado para interceptarlas.

No obstante, y con independencia de su anclaje en alguno de los preceptos constitucionales anteriormente mencionados, lo importante a efectos de nuestro estudio es destacar que el reconocimiento del derecho al secreto profesional como garantía de la confidencialidad de las

66 Así lo señala R. AlLendesalAZAR: «la garantía de la confidencialidad de las comunicaciones entre abogado y cliente entronca (...) con una mejor aplicación del Derecho y de la Administración de la justicia. El legal privilege pretende favorecer la comunicación abierta entre el abogado y su cliente, para que aquél pueda prestar un asesoramiento completo e independiente, lo cual, debería favorecer el mayor respeto a las leyes»; vid. "Confidencialidad de las comunicaciones abogado y cliente, y eficacia de la labor inspectora: dos principios a la búsqueda de equilibrio», Gaceta Jurídica de la Unión Europea y de la Competencia, núm. 7, enero-febrero 2009, pág. 86.

67 Sobre el secreto profesional, vid. S. Muñoz Machado, «El secreto médico», RAP, núm. 79, 1976, págs. 139 y ss.; E. GÓMEZ-REINO Y CARNOTA, «El secreto profesional de los periodistas», RAP, núms. 100-102, I, 1983, págs. 611 y ss.; J. M. ${ }^{a}$ MichaviLA NúÑEZ, «El derecho al secreto profesional y el artículo 24 de la Constitución. Una visión unitaria de la institución», en Estudios sobre la Constitución española. Homenaje al Prof. Eduardo García de Enterría, vol. II, Civitas, Madrid, 1991, págs. 1416 y ss.; J. M. ${ }^{a}$ Baño LEón, Potestades administrativas..., cit., págs. 201 y ss. 
comunicaciones entre las empresas objeto de investigación por las autoridades de competencia y sus abogados debe ser interpretado y protegido teniendo en cuenta una serie de factores. Concretamente, este tipo de comunicaciones entre abogado y empresas tendrá la protección examinada cuando: A) este tipo de comunicaciones entre el abogado y la empresa se hacen a propósito del ejercicio de los derechos de defensa de la misma; y B) a su vez, bajo el concepto de abogado sólo puede entenderse comprendido el que desarrolla sus funciones legales independientemente de la actividad normal de la empresa. Al examen de estos aspectos dedicaremos los epígrafes siguientes.

\section{A) Tipo de comunicaciones que se encuentran comprendidas bajo la confidencialidad}

Las comunicaciones intercambiadas entre los abogados y sus clientes deben ser de carácter confidencial o secreto para que puedan caer dentro del ámbito de protección del secreto profesional. A sensu contrario, aquellas comunicaciones que no se hayan realizado bajo el manto de la confidencialidad o que, siendo en un principio confidenciales, hayan perdido este carácter como resultado de su excesiva distribución o fotocopia no tienen la protección que les depara la jurisprudencia comunitaria. De todas formas, en aquellos supuestos en que existe un intercambio de documentos e información entre un grupo de empresas con un mismo abogado que las representa legalmente, esta información no pierde su condición de confidencialidad por el mero hecho de su amplia distribución, como ha señalado el TJUE en su sentencia $A M \& S$ Europe.

Igualmente, el Derecho comunitario de la Competencia garantiza la confidencialidad de la correspondencia entre abogado y su cliente. No obstante, esta garantía no es absoluta. El TJUE fija dos condiciones para que pueda ser operativa: en primer lugar, que se trate de correspondencia intercambiada en el marco y con los fines del derecho a la defensa del cliente; $y$, en segundo lugar, que se trate de abogados independientes, es decir, no ligados a la empresa por un vínculo empresarial $^{68}$. Estas dos condiciones delimitan el alcance del derecho de las empresas y asociaciones de empresas a la protección de la confidencialidad de la correspondencia con sus abogados. Constituyen, por tanto, un límite al poder de inspección de los agentes de competencia.

68 STJCE $A M$ \& $S$ Europe y, más recientemente, STPI de 17 de septiembre de 2007, Akzo Nobel Chemicals Ltd, asuntos acumulados T-125/03 y T-253/03. 
En relación a la condición referente a que los documentos que tienen carácter confidencial deben circunscribirse a aquellos vinculados directamente con el derecho a la defensa del cliente, el TJUE declara que la normativa comunitaria

«vela por la salvaguarda del pleno ejercicio de los derechos de defensa, siendo la protección de la confidencialidad de la correspondencia entre abogado y cliente un complemento necesario de dichos derechos. Esta protección debe entonces, ser extendida, para ser eficaz, a la cobertura de pleno derecho, de toda correspondencia intercambiada tras el inicio del procedimiento (...), susceptible de conducir a una decisión imponiendo a una empresa una sanción pecuniaria; tiene que poder ser igualmente extendida a la correspondencia anterior que tenga un vínculo de conexión con el procedimiento en cuestión» ${ }^{69}$.

También se ha extendido el derecho al secreto de la información confidencial intercambiada entre la empresa y su abogado a aquellos documentos internos de la empresa que contienen reflexiones o sugerencias facilitadas por el abogado. Así, en el auto del TPI, de 4 de abril de 1990, Hilti se establece que

«el principio de protección acordado para las comunicaciones entre el abogado y su cliente no podría ser ignorado por el solo motivo de que el contenido de estas comunicaciones y de los avisos jurídicos ha sido recogido en documentos internos de la empresa. Por ello, atendida su finalidad, el principio de protección de las comunicaciones entre abogado y cliente debe ser contemplado como si se extendiera igualmente a las notas internas que se limitan a reproducir el texto o contenido de estos comunicados ${ }^{70}$.

\section{B) La inexistencia de un vínculo salarial entre empresa y abogado}

Como se ha examinado, una de las notas o condiciones esenciales destacadas por la jurisprudencia comunitaria con el fin de delimitar la

69 Ibidem.

70 Asunto T-30/89. Sobre este punto, vid. T. K. GiannaKopoulos, Safeguarding companies..., cit., págs. 80 y ss.; J. M. TRAYTER JimÉNEZ, La defensa de las empresas frente a las sanciones de la Administración europea, Bosch, Barcelona, 1988, págs. 27 y ss. 
garantía de la confidencialidad de las comunicaciones entre las empresas sujetas a inspección y sus abogados es la relativa a la naturaleza del vínculo que existe entre ambos. En este sentido, se ha destacado que no debe existir una vinculación salarial entre empresa y abogado para que se pueda esgrimir el carácter confidencial de determinadas comunicaciones.

Así, el TJUE, en la ya citada sentencia $A M \& S$ Europe, sostiene al respecto que

«cabe precisar que la exigencia relativa a la posición y a la cualidad de abogado independiente que debe revestir el asesoramiento que emana de la correspondencia susceptible de ser protegida, procede de una concepción del papel del abogado, considerado como un colaborador de la justicia y llamado a facilitar, con toda independencia y el interés superior de la misma, la asistencia legal que el cliente necesita. Esta protección tiene como contrapartida la disciplina profesional, impuesta y controlada en el interés general por las instituciones habilitadas para este fin. Esta concepción responde a las tradiciones jurídicas de los Estados miembros y también se encuentra en el ordenamiento jurídico comunitario».

De este modo, el TJUE opta por dar preferencia al criterio del vínculo salarial entre el abogado y el cliente, con la finalidad de ver si las comunicaciones entre ambos caen o no bajo la protección de la confidencialidad, frente al denominado criterio subjetivo, en base al cual, debido a que todos los abogados por razón del ejercicio de su profesión se encuentran sometidos al secreto profesional y a la observancia de unas normas éticas o deontológicas, debería ser indiferente la relación que tienen con las empresas y todos los documentos y comunicaciones que tuvieran con las mismas estarían sujetos a la cláusula de confidencialidad.

En definitiva, a pesar de las críticas que sobre esta doctrina jurisprudencial han vertido algunos sectores, la realidad es que sólo van a encontrarse protegidas por la confidencialidad aquellas comunicaciones entre empresas y abogados cuando éstos no tengan una relación o vínculo salarial con aquéllas. Es decir, va a ser la nota de independencia de la relación entre abogados y empresas la que va a prevalecer a este respecto ${ }^{71}$.

71 Así, por ejemplo, P. DufFy, que se ha mostrado crítico con esta jurisprudencia, ha propuesto que las empresas que tengan dentro de su organización interna un departamento jurídico deberían separarlo de la misma con el fin de que pueda tener la nota de independen- 
Finalmente, cabe señalar que la inmunidad así delimitada se otorga indistintamente a la correspondencia de todos los abogados colegiados o autorizados para ejercer en uno de los Estados miembros, con indiferencia del Estado miembro en que la empresa resida.

\section{BIBLIOGRAFÍA}

AllendesalazAR, R.: «Confidencialidad de las comunicaciones abogado y cliente, y eficacia de la labor inspectora: dos principios a la búsqueda de equilibrio», Gaceta Jurídica de la Unión Europea y de la Competencia, núm. 7, enero-febrero 2009.

ARAuJo, M.: «El tratamiento confidencial de determinada información», en La modernización del Derecho de la Competencia (dirs. S. Martínez Lage y A. Petitbó JuAN), Colección Derecho, Fundación Rafael del Pino, Madrid, 2005.

Baño León, J. M. ${ }^{\text {a }}$ : Potestades administrativas y garantías de las empresas en el Derecho español de la competencia, McGraw-Hill, Madrid, 1996.

CASES, Ll.: Derecho administrativo de defensa de la comptencia, Marcial Pons-ICO, Madrid, 1995.

Christoforou, T.: «Protection of legal privilege in EEC Competition Law: the imperfections of a case», FILJ, vol. 3, 1985.

Connolly, N.: «Legal privilege in the European Communities after the AM \& S Case», ECLR, núm. 2, 1982.

Costas, J.: «La confianza legítima en la actuación de las Administraciones Públicas como límite al Derecho de Defensa de la Competencia», en Derecho de la Competencia y regulación en la actividad de las Administraciones Públicas (dir. J. Guillén Caramés), Civitas-Thomson Reuters, Madrid, 2011.

DUFFY, P.: «Legal privilege and community Law», NLJ, vol. 2, 1982.

Embid Irujo, A.: El ciudadano y la Administración, MAP, Madrid, 1994.

- La protección jurídica del ciudadano. Estudios en Homenaje al Profesor Jesús González Pérez, I, Civitas, Madrid, 1993.

FAUll, J., y NiKPaY, A.: The EC Law of Competition, Oxford University Press, 2007.

FERnÁndez Ramos, S.: La actividad administrativa de inspección, Comares, Granada, 2002.

GARCíA MACHO, R.: Secreto profesional y libertad de expresión del funcionario, Tirant lo Blanch, Valencia, 1994.

García UReta, A.: La potestad inspectora de las Administraciones Públicas, Marcial Pons, 2006.

GiAnNOKOPOULOS, T. K.: Safeguarding companies in competition and anti-dumping/ anti-sybsidies proceedings, Kluwer Law International, 2004.

Gómez-REINo y CARNOTA, E.: «Las facultades de investigación de la administración y los derechos fundamentales con especial referencia al Derecho de la Competencia», ICR, núm. 650, 1987.

— «El secreto profesional de los periodistas», RAP, núms. 100-102, I, 1983.

GonzÁlEz DuRANTEZ, H.: «Los límites a los requerimientos de información de la Comisión Europea», en Problemas prácticos y actualidad del Derecho de la Competencia (Anuario 2014), Thomson Reuters-Civitas, 2014.

cia que reclama el TJCE para que determinadas comunicaciones puedan ser consideradas confidenciales y no se encuentren sujetas a inspección; vid. "Legal privilege and community Law», NLJ, vol. 2, 1982, págs. 580 y ss. 
Goyder. D. G.: EC Competition Law, Oxford University Press, 2003.

GuILlÉn CARAmés, J.: Régimen jurídico de la inspección en Derecho de la Competencia, Aranzadi-Thomson Reuters, 2010.

- «Reflexiones sobre la finalidad y alcance de la actividad de promoción en el Derecho de la Competencia», en La reforma de los contratos de distribución comercial, La Ley-IDMC, 2013.

- «Transparencia y acceso a la información pública en el Derecho de la Competencia», en Régimen jurídico de la transparencia en el sector público (coords. J. Valero Torrijo y M. Fernández Salmerón), Aranzadi-Thomson Reuters, 2014.

Jimenez Laiglesia, J. M. a , y Masía, J.: «Promoción de la Competencia», en Derecho de la Competencia y regulación en la actividad de las Administraciones Públicas (dir. J. GuILlÉn Caramés), Civitas-Thomson Reuters, Madrid, 2011.

LAGUNA DE PAZ, J. C.: «Las potestades administrativas de investigación en materia de defensa de la competencia», Revista de Derecho de la Competencia y la Distribución, núm. 5, 2009.

LEÓN JiMÉNEZ, R.: «Los derechos fundamentales de las empresas en el procedimiento de competencia comunitario», en Derecho de la Competencia Europeo y Español, vol. III, Dykinson-URJC, Madrid, 2002.

Llopis ReYNA, E.: «Intercambio de información entre Administraciones Públicas y derechos de defensa», REDA, núm. 83, 1994.

LóPEZ BENÍTEZ, M.: «Algunas consideraciones en torno a la práctica de una información reservada en los procedimientos sancionadores en materia de defensa de la competencia», en Cuestiones actuales del procedimiento sancionador en Derecho de la Competencia (dir. J. GuIllén CARAMÉs), Civitas-Thomson Reuters, 2013.

Martín de PaBlos, M. A.: «Transparencia, comunicación y defensa de la competencia», en Anuario de la Competencia 2011-2012, Fundación ICO-UAB.

Martín Pastor, J.: "Artículo 42», en Comentario a la Ley de Defensa de la Competencia, Civitas-Thomson Reuters, 3. ${ }^{\mathrm{a}}$ ed., 2012.

- "Artículo 39», en Comentario a la Ley de Defensa de la Competencia, CivitasThomson Reuters, 3. ${ }^{\mathrm{a}}$ ed., 2012.

Martín ReBollo, L.: "Régimen de responsabilidades del inspector de consumo como funcionario en los ámbitos civil, penal y administrativo. Referencia al deber de sigilo», en La inspección de consumo en el contexto de la actuación administrativa, Gobierno Vasco, Vitoria, 1992.

Martín-Retortillo BaQuer, L.: La Europa de los derechos humanos, CEPC, Madrid, 1998.

- La interconexión de los ordenamientos jurídicos y el sistema de fuentes del Derecho, discurso de ingreso en la Real Academia de Jurisprudencia y Legislación, Madrid, 2004.

MENÉNDEZ, A.: «Los derechos del administrado en los procedimientos de aplicación del Derecho de la Competencia», REDA, núm. 77, 1993.

MichaVILA NúÑEz, J. M. ${ }^{\text {a: }}$ "El derecho al secreto profesional y el artículo 24 de la Constitución. Una visión unitaria de la institución», en Estudios sobre la Constitución española. Homenaje al Prof. Eduardo García de Enterría, vol. II, Civitas, Madrid, 1991.

Montero Pascual, J. J.: La Comisión Nacional de los Mercados y la Competencia, Tirant lo Blanch, 2013.

MonTI, M.: «Towards the apllication of article 81 (3) by National Courts», en Anuario de Defensa de la Competencia 2000, ICO-Marcial Pons, 2001.

Ortiz Blanco, L.: EC Competition Procedure, Oxford University Press, 2013. 
Palao TABOAda, C.: «La potestad de obtención de información de la Administración tributaria y sus límites», en Estudios de Derecho y Hacienda. Homenaje a César Albiñana, vol. II, Ministerio de Economía y Hacienda, Madrid, 1987.

Parejo Alfonso, L.: «El nuevo sistema de defensa de la competencia. Algunas cuestiones generales sobre su fundamento constitucional y su organización específica en una Administración independiente», en Derecho de la Competencia, La Ley, 2008.

Pedraz Calvo, M.: «La confidencialidad del expediente administrativo», en Anuario de la Competencia 1997, Marcial Pons-ICO, Madrid, 1998.

RAMs Ramos, L.: «El acceso a los expedientes sancionadores en materia de Derecho de la Competencia», en Cuestiones actuales del procedimiento sancionador en Derecho de la Competencia (dir. J. GuILlén CARAmés), Civitas-Thomson Reuters, 2013.

RAZQUin LizARRAga, M. M. ${ }^{\text {a }:}$ La confidencialidad de los datos empresariales en poder de las Administraciones Públicas (Unión Europea y España), Iustel, 2013.

Rebollo PUig, M.: "Potestades inspectoras y sancionadoras», en La Comisión Nacional de los Mercados y de la Competencia (dir. M. CARLón RuIz), Civitas-Thomson Reuters, 2014.

- "La actuación inspectora», en Función inspectora (dir. J. J. Díez SÁnchez), INAP-AEPDA, 2013.

RitTER, L., y BRAUn, D.: European Competition Law, Kluwer Law International, 2004.

SaInz Moreno, F.: «Secreto e información en Derecho Público», en Estudios sobre la Constitución española. Homenaje al Prof. Eduardo García de Enterría, vol. II, Civitas, Madrid, 1991.

Sala Arquer, J. M.: "Artículo 27 LDC», en Comentario a la Ley de Defensa de la Competencia, Civitas-Thomson Reuters, 2012.

- "Artículos 25 y 26», en Comentario a la Ley de Defensa de la Competencia, Civitas-Thomson Reuters, Madrid, 2012.

Soriano Garcia, J. E.: La defensa de la competencia en España, Iustel, 2007.

- Derecho Público de la Competencia, IDELCO-Marcial Pons, 1998.

Trayter Jiménez, J. M.: La defensa de las empresas frente a las sanciones de la Administración europea, Bosch, Barcelona, 1988.

Usher, J.: «Legal Professional privilege and confidentiality in EEC Competition Proceedings: the judgement of the European Court», JBL, 1982.

VAN BAEL \& BelLIS: Competition Law of the European Community, Kluwer Law International, The Hague, 2005.

VERgEZ, C.: «Artículo 43», en Derecho español de la competencia, Bosch, 2008.

VERVAELE, A. E.: «Regulación comunitaria y aplicación operacional de los poderes de investigación, obtención y utilización de pruebas en relación a la infracción de intereses financieros de la Comunidad Europea», RVAP, núm. 52, 1998.

VILA Costa, B.: «Los derechos de defensa en el Derecho Comunitario», RIE, vol. 17, núm. 2, 1990. 
